\title{
Seismic Analysis of Steel Cylindrical Liquid Storage Tank Using Coupled Acoustic-Structural Finite Element Method For Fluid-Structure Interaction
}

\author{
Aruna Rawat, Vasant Matsagar and A. K. Nagpal \\ Department of Civil Engineering, Indian Institute of Technology (IIT) Delhi, Hauz Khas, New Delhi - 110016 , \\ India.
}

(Received 24 March 2018; accepted 22 November 2018)

A seismic analysis of ground-supported, three-dimensional (3-D) rigid-base steel cylindrical liquid storage tank is investigated, using a coupled acoustic-structural finite element (FE) method for fluid-structure interaction (FSI). In this method, the contained liquid in the tank is modelled using acoustic elements and the cylindrical tank is modelled using shell elements. The impulsive and convective terms are estimated separately by using the appropriate boundary conditions on the free surface of the liquid. The convergence and validation studies of the proposed FE model are conducted by comparing the results reported in the literature. The parametric studies are performed for rigid and flexible tanks for the varying slenderness of the open roof tanks. The sloshing displacement and base shear time history responses are evaluated for the 3-D tanks subjected to harmonic unidirectional ground motions. Further, the results are compared with the commonly used two and three lumped-mass models of the tank. Moreover, the seismic response quantities of the tank subjected simultaneously to the bi-directional horizontal components of earthquake ground motion are also investigated using the 3-D FE model, and the response quantities are compared with the lumped-mass models. The results obtained from the 3-D FE model and lumpedmass model are in close agreement. The average percentage difference in the 3-D FE and lumped-mass models for maximum sloshing displacement prediction is 15 percent to 20 percent and that for the base shear is about 4 to 10 percent, in the case of the uni-directional harmonic ground motions. It is concluded that the sloshing displacement is not affected by the tank flexibility, but the impulsive hydrodynamic pressure and the impulsive component of the base shear increases with the tank flexibility.

\section{NOMENCLATURE}

$\ddot{u}$
$\dot{u}_{\text {out }}$
$\nabla$
$\phi$
$A_{c}$
$u_{c}$
$\omega_{c}$
$\ddot{x}_{g}(t)$
$1 / k_{1}$

$1 / c_{1}$
$\dot{p}$
$I_{1}(\cdot) ; I_{1}^{\prime}(\cdot)$
$a_{0}$
$a_{n}$

$c$
$c_{c}$
$c_{i}$
$F$
$F_{e}$
$F_{f}$

amplitude nodal acceleration

particle velocity in outward normal

direction of the acoustic medium

Laplacian operator

velocity potential

convective pseudo-acceleration

displacement of the convective mass

frequency of the convective mass

ground acceleration

proportionality constant between

the displacement and the pressure

in the normal direction to the surface

proportionality constant between the velocity

and the pressure in normal direction to the surface

time rate of change of the acoustic pressure

modified Bessel function of first order

and its derivative, respectively

acceleration component along the direction

vector for an outward pointing normal $n$

to the fluid region

speed of sound in liquid

damping constant of the convective mass

damping constant of the impulsive mass

generalized force

external nodal forces

amplitude of displacement
$F_{p r} \quad$ nodal forces exerted on the tank wall due to the pressure imparted by the oscillation of the liquid contained in the tank

$g \quad$ acceleration due to gravity

$h \quad$ small amplitude wave or sloshing height

$H_{c} \quad$ height of convective mass from base of the tank

$H_{i} \quad$ height of the impulsive mass from the base of the tank

$H_{L} \quad$ liquid height in the tank

$I \quad$ internal forces resisted by the tank liquid materials

$K$ bulk modulus of liquid

$k_{c} \quad$ convective spring stiffness

$k_{i} \quad$ impulsive spring stiffness

$M \quad$ nodal mass

$m_{c} \quad$ convective mass

$m_{i} \quad$ impulsive mass

$m_{r} \quad$ rigid mass

$p \quad$ hydrodynamic pressure at any point

$R \quad$ radius of the tank

$S \quad$ aspect ratio of the tank

$t \quad$ time

$v \quad$ velocity distribution of liquid

$\rho_{L} \quad$ mass density of the liquid

$\omega \quad$ excitation frequency

$\omega_{f} \quad$ forcing frequency

$U_{S}$ nodal displacement

$P_{A} \quad$ nodal pressure

$M_{S} \quad$ mass matrix of the structural domain

$C_{S} \quad$ damping matrix of the structural domain

$K_{S}$ stiffness matrix of the structural domain

$M_{A} \quad$ mass matrix of acoustic fluid domain

$C_{A} \quad$ damping matrix of acoustic fluid domain

International Journal of Acoustics and Vibration, Vol. 25, No. 1, 2020 


\begin{tabular}{ll}
\hline \hline$K_{A}$ & stiffness matrix of acoustic fluid domain \\
$Q_{S A}$ & spatial coupling matrix \\
$T$ & transpose \\
$F_{q}$ & fluid force
\end{tabular}

\section{INTRODUCTION}

Liquid storage tanks are very important components of civic, industrial, and agricultural services. These civil structures are used in water supply facilities, firefighting systems, and nuclear reactors for storage of various types of liquid. Various shapes of the tank are used for storage of liquid, but of them cylindrical tanks are most extensively utilized. The cylindrical tanks are easy and economical to fabricate, and are structurally efficient in sustaining the hydrostatic and hydrodynamic pressures produced by the contained liquid.

The tanks subjected to earthquake-induced base excitations have shown various modes of failure. The most common modes of the failure observed are in the form of elephantfoot buckling, diamond-shaped buckling of the tank wall, sliding of the base, uplifting of the base, roof damage, foundation failure, and failure of the supply or outlet systems. Such failures typically lead to economic losses, resulting in disastrous consequences, and if flammable liquids or hazardous materials are spread, pollution of the surrounding air and soil may occur due to triggering of the secondary hazard. Several ground-supported and elevated tanks suffered severe damages and some failed with disastrous consequences during the past earthquakes, such as the 1933 Long Beach earthquake; the 1952 Kern County, California earthquake; ${ }^{38,61}$ the 1964 Alaska earthquake; ${ }^{22}$ the 1977 San Jan Argentina earthquake; ${ }^{41}$ the 1979 Imperial County earthquake; ${ }^{16,25}$ the 1983 Coalinga earthquake; ${ }^{42}$ the 1994 Northridge earthquake; ${ }^{20}$ and the 2003 Tokachi-Oki earthquake in northern Japan. ${ }^{27}$

Over the past decades, numerous analytical, numerical, and experimental studies have been carried out on the seismic analyses of the liquid storage tanks with an objective of improving the seismic safety by reducing the risk of damage or failure of the tanks. Housner developed an analytical model assuming the fluid to be incompressible, inviscid, irrotational, and considering that the displacements were small and tank walls were rigid. ${ }^{29,30}$ In this model, a fixed/anchored groundsupported cylindrical tank was modelled using the lumpedmass approach with two degrees-of-freedom, such as convective (i.e. sloshing) and impulsive components of the vibrating liquid column. This model has been widely used in the contemporary codes and standards for analysing the rigid wall tanks. During the 1964 Alaska earthquake, several petrochemical tanks were severely damaged, which revealed that the rigid tank wall behaviour was a gross assumption and the tank wall flexibility does indeed considerably influence the dynamic response of the liquid storage tank. This motivated many researchers to study the effect of the tank wall flexibility on the seismic behaviour of tanks. Veletsos ${ }^{62}$ and Veletsos and Yang $^{63}$ developed a flexible anchored tank model and concluded the hydrodynamic pressure was dependent on the flexibility of the tank wall and that the convective (i.e. sloshing) response is insensitive to the tank wall flexibility. Clough ${ }^{10}$ and Clough et al. ${ }^{11}$ performed a series of experiments on largescaled thin-walled liquid storage tanks. Haroun and Housner showed effective application of the boundary integral theory to model the liquid column and ring-shaped finite elements for the tank shell to conduct dynamic analysis of the deformable cylindrical tanks and compared the responses with the rigid tank wall. ${ }^{25}$ Subsequently, a three lumped-mass model for the ground-supported tanks was developed that duly takes the flexibility of the tank wall into account. ${ }^{26}$ Corresponding to the convective, impulsive, and rigid components, developed design charts for estimating the values of the three lumpedmass model in the ground-supported cylindrical liquid storage tanks. $^{23,24}$ In this vibro-mechanical model, the tank wall was considered flexible, i.e., deformable through the three lumpedmasses. Full-scale tests on the water storage tank were conducted to determine the natural frequencies and mode shapes of vibration, subsequently leading to the development of the design charts.

Barton and Parker investigated the seismic response of the anchored and unanchored tanks subjected to unidirectional earthquake using a finite element (FE)-based computer code with the added mass method and three-dimensional (3-D) FE to model the fluid. ${ }^{5}$ Malhotra and Veletsos studied the response of the unanchored ground-supported liquid storage tanks and found that the liquid height to tank radius was the most important parameter governing the uplifting response of the tanks. ${ }^{39}$ Kim et al. employed the Rayleigh-Ritz method for conducting the dynamic analysis of partially filled two-dimensional (2-D) and 3-D rectangular tanks subjected to horizontal or vertical earthquake excitations, considering rigid and flexible tank walls. $^{34}$ Mackerle presented a bibliography on finite element method (FEM) and boundary element method (BEM) used for solving the fluid-structure interaction (FSI) problems. ${ }^{37} \mathrm{Ham}$ dan presented a review of the seismic behaviour and design guidelines for the ground-supported cylindrical steel liquid storage tanks. ${ }^{21}$ A simplified procedure was developed for seismic analysis of the liquid storage tank by Malhotra et al., considering first convective and impulsive modes. ${ }^{40}$ This procedure takes into account convective (sloshing) and impulsive actions of the contained liquid in the flexible steel or concrete tanks fixed to rigid foundations. Virella et al. studied the dynamic buckling analysis of the ground-supported steel tanks with conical roofs that were anchored to the foundation, all of which were subjected to horizontal components of earthquakes. ${ }^{66}$ The dynamic buckling analysis was carried out using finite element (FE) software. The different height-to-diameter $(H / D)$ ratios were considered for the analysis.

Jaiswal et al. reviewed the provisions made in various international codes for seismic analysis and design of the liquid storage tanks. ${ }^{32}$ Shahverdiani et al. studied the behaviour of the cylindrical concrete tanks under harmonic excitation, using the FEM and concluded that wall thickness governs the tank wall flexibility. ${ }^{59}$ Goudarzi and Sabbagh-Yazdi compared the seismic responses of the cylindrical tank subjected to unidirectional earthquake excitation using spring-mass and FE models. ${ }^{19}$ Ghaemmaghami and Kianoush studied the effects of wall flexibility on the response of the rectangular tank subjected to horizontal and vertical seismic excitations. ${ }^{17} \mathrm{Re}-$ bouillat and Liksonov reviewed recent numerical studies on the FSI problems. ${ }^{52}$ Ozdemir et al. carried out experimental studies on seismic analysis of the anchored and unanchored steel tanks, and these experimental results were used to verify the non-linear numerical procedure proposed. ${ }^{47}$ Bayraktar et al. studied the effect of the FE model updating on the earthquake behaviour of the steel cylindrical tanks with the FSI effects. ${ }^{6}$ The analytical and experimental dynamic characteristics of the tanks were also compared. It was observed that the 
displacements and the stresses after model updating were more efficiently evaluated than prior to the model updating. Amiri and Sabbagh-Yazdi carried out the experimental and numerical investigations on the dynamic parameters, natural frequencies, and mode shapes of the fixed-roof ground-supported tall steel storage tanks. ${ }^{2}$ Hosseinzadeh et al. studied 161 existing tanks in an oil refinery complex and classified them into 24 groups. ${ }^{28}$ These tanks were studied in light of the API 6502008 code and the numerical FE models. Failure modes and dynamic characteristics of these tank models were evaluated using the numerical FE analysis and compared with the code provisions.

Moslemi and Kianoush carried out a dynamic analysis of ground-supported concrete cylindrical tanks using FEM. ${ }^{44}$ Saha et al., ${ }^{55,56}$ and Panchal and Soni ${ }^{48}$ studied the seismic response of the ground-supported base-isolated liquid storage tanks. Elkholy et al. described various optimal FE measures such as the types and number of elements that can effectively determine the coupled natural frequencies, and various mode shapes for the dynamic behaviour of the liquid storage tank. ${ }^{12}$ Ormeno et al. used the seismic ground motion scaling procedures for the linear time history analysis of the tanks. ${ }^{46}$ They compared results of base shear, overturning moment, and wall stresses for the ASCE/SEI 7-10, ${ }^{4}$ Eurocode 8, ${ }^{13}$ and NZS $1170.5^{45}$ code recommendations. Ruiz et al. developed a simplified sloshing model (SSM) which was computationally efficient for evaluating the dynamic behaviour of the liquid storage tanks. ${ }^{54}$ Park et al. carried out an experimental work to study the dynamic behaviour of the cylindrical tank subjected to the earthquake excitations. ${ }^{49}$ It was observed that the occurrence of beam-type vibration modes, oval-type vibration modes, and combined modes were dominating the vibration of the tank. Godoy presented a complete review on the buckling problems in vertically above-ground tanks under static and quasi-static loads, including uniform pressure, wind, settlement of foundation, and fire. ${ }^{18} \mathrm{Kim}$ et al. numerically analysed the effect of sloshing impact in prismatic tanks under horizontal excitation. ${ }^{33}$ It was found that the variable pressure loads were changed by adopting the upper and lower chamfered shapes of the tank. Spritzer and Guzey ${ }^{60}$ reviewed the results obtained by following the API 650's Annex $E^{2}$ for designing aboveground steel storage tanks subjected to earthquakes and compared the design provisions with the equivalent New Zealand and Japanese documents. Kotrasová and Kormanikova investigated the seismic responses of large and small tanks fixed to rigid foundations using the procedure given in Eurocode 8. ${ }^{35}$

Fiore et al. carried out seismic analysis of a spherical pressure vessel using the FE model and a simplified single degreeof-freedom (SDOF) inverted pendulum model. ${ }^{15}$ These models took into consideration the influence of sloshing effects and soil-structure interaction (SSI). Kormanikova and Kotrasová investigated the seismic response of the liquid storage laminated composite tank. ${ }^{35}$ The horizontal seismic load acting at the base of the tank was considered using the elastic response spectrum. Phan et al. studied the seismic vulnerability of an unanchored steel storage tank based on the fragility analysis using aleatoric and epistemic uncertainties. ${ }^{50}$ Rahmati et al. studied the probabilistic stability of pipes conveying fluid with uncertain flow velocity in time domain. ${ }^{51}$

The previous literatures reported the use of acoustic elements for modelling liquid in the FE analysis. Morand and Ohayon described a number of FE formulations to model an acoustic fluid for solving the FSI problems, namely the displacement formulation, the displacement potential and pressure formulation, and the velocity potential formulation. ${ }^{43}$ Wang and Bathe used mixed FE formulations for the acousticstructure interaction problems, in which fluid was modelled using acoustic elements. ${ }^{67}$ Everstine reviewed the different FE formulations used for solving the structural acoustic and FSI problems. ${ }^{14}$ Virella et al. studied linear sloshing effects in the two-dimensional (2-D) rectangular tanks subjected to horizontal harmonic motion using the acoustic elements in the linear FE model. ${ }^{64}$ Subsequently, they investigated the dynamic response of the cylindrical tanks partially filled with liquid under horizontal ground excitations. ${ }^{65}$ The liquid was modelled using two different techniques: the added mass formulation and acoustic fluid elements based on linear wave theory.

It is rather unclear from the reported literature what the influence of the tank wall flexibility is on the behaviour of the liquid when the tank is subjected to seismic base excitations. Further, the efficacy of the modelling approaches in capturing the highly non-linear sloshing behaviour of the contained liquid and accurately predicting forces induced in the tank wall due to the static and dynamic components of the vibrating liquid column is yet to be investigated thoroughly. Hence, it is deemed important to conduct a seismic analysis of the cylindrical liquid storage tank through different modelling approaches and study its effect on the dynamic response quantities.

In the present study, in view of the aforementioned requirements, the seismic analysis of 3-D ground-supported cylindrical liquid storage tanks is investigated using the coupled acoustic-structural (CAS) approach in the FEM. Using the developed FE model, the convective and impulsive components are modelled separately by applying appropriate boundary conditions on the free liquid surface. The results obtained from the coupled acoustic-structural FE method are compared with the commonly used mechanical analogue, lumped-mass model of the liquid storage tanks. The effect of the tank wall flexibility is also investigated by comparing the responses for the rigid and flexible tanks subjected to seismic ground motion.

The specific objectives of the present investigation are: (i) to study the sloshing and base shear responses of the fixed-base, rigid, and flexible cylindrical tanks subjected to unidirectional harmonic ground motion using three-dimensional (3-D) finite element (FE) and mechanical (discrete) lumped-mass models; (ii) to study the dynamic response of the 3-D rigid and flexible tanks subjected to bi-directional (two horizontal) components of the earthquakes and compare their response quantities with the two and three lumped-mass models, respectively; (iii) to study the seismic response of the broad and slender tanks with different aspect ratios; and (iv) to compare the hydrodynamic pressure developed along the rigid and flexible tank walls under bi-directional components of the earthquakes.

\section{GOVERNING EQUATIONS OF MOTION FOR LIQUID STORAGE TANK}

In fluid dynamics, for the irrotational, inviscid, frictionless liquid, the velocity distribution of liquid, $v_{x}=\frac{\partial \phi}{\partial x}, v_{y}=$ $\frac{\partial \phi}{\partial y}, v_{z}=\frac{\partial \phi}{\partial z}$ may be represented as a gradient of the velocity potential, $\phi(x, y, z, t)$, which satisfies the Laplace equation, and can be written in general 3-D space $(x, y, z)$ as

$$
\frac{\partial \phi^{2}}{\partial x^{2}}+\frac{\partial \phi^{2}}{\partial y^{2}}+\frac{\partial \phi^{2}}{\partial z^{2}}=0 .
$$


The motion of the liquid within the tank is represented in terms of the continuity and boundary conditions at the interface of the tank and liquid as well as at the free liquid surface. The wave equation in terms of the hydrodynamic pressure is given as

$$
\nabla \cdot \nabla p(x, y, z, t)=0
$$

where $\nabla \cdot \nabla$ is the Laplacian operator, and hydrodynamic pressure, $p$ at any point and time, $t$ is given as

$$
p(x, y, z, t)=-\rho_{L} \frac{\partial \phi}{\partial t} ;
$$

where $\rho_{L}$ is the mass density of the liquid. At the rigid base of the tank, the boundary condition is given as

$$
\frac{\partial \phi}{\partial z}=0 \quad \text { at } \quad z=0 \text { (at the base of the tank). }
$$

The boundary condition along fluid-structure interface is given as

$$
\frac{\partial p(x, y, z, t)}{\partial n}=-\rho_{L} a_{n}(x, y, z, t)
$$

where $a_{n}$ is the acceleration component along the direction vector for an outward pointing normal $n$ to the fluid region. On the free surface, it is assumed that the liquid forms a small amplitude wave, $h$, relative to the mean surface. ${ }^{68}$ This condition is known as linearized surface wave condition, which accounts for gravity waves to be included in the analysis. The boundary condition at $z=H_{L}$ is given as

$$
\frac{1}{g} \frac{\partial^{2} p(x, y, z, t)}{\partial t^{2}}+\frac{\partial p(x, y, z, t)}{\partial z}=0 \quad \text { at } \quad z=H_{L} ;
$$

where $g$ is the acceleration due to gravity, and $H_{L}$ is liquid height in the tank. The pressure developed by the wave height, $h$ is given as $p=\rho_{L} g h$, at the free surface of the liquid. Alternatively, at the free surface of liquid, the boundary condition is given as

$$
p=0 \quad \text { at } \quad z=H_{L} .
$$

By inserting the boundary condition of Eq. (7) into Eq. (6), the impulsive component of the hydrodynamic pressure is obtained. The total response is then sum of the convective and impulsive responses.

In the present study, the coupled acoustic-structural FE method is used for seismic analyses of the liquid storage tank. The acoustic wave governing equation in terms of the hydrodynamic pressure, $p$ as an independent variable in the following equation, a homogenous linear wave equation also known as the Helmholtz equation, which is given as

$$
\frac{\partial^{2} p}{\partial t^{2}}-c^{2} \nabla^{2} p=0
$$

where $c$ is the speed of sound in liquid that is given as, $c=$ $\sqrt{K / \rho_{L}}$, and $k$ is the bulk modulus of the liquid. ${ }^{68}$ In Eq. (8), displacement degrees-of-freedom are absent; hence, the computational time required for the coupled acoustic-structural FE method is reduced.

\section{MODELLING OF LIQUID STORAGE TANK}

In the present study, the cylindrical liquid storage tank is modelled using coupled acoustic-structural (CAS) approach in the finite element method (FEM) ${ }^{64,65}$ and the seismic response quantities are compared with the commonly used mechanical lumped-mass model of the tank.

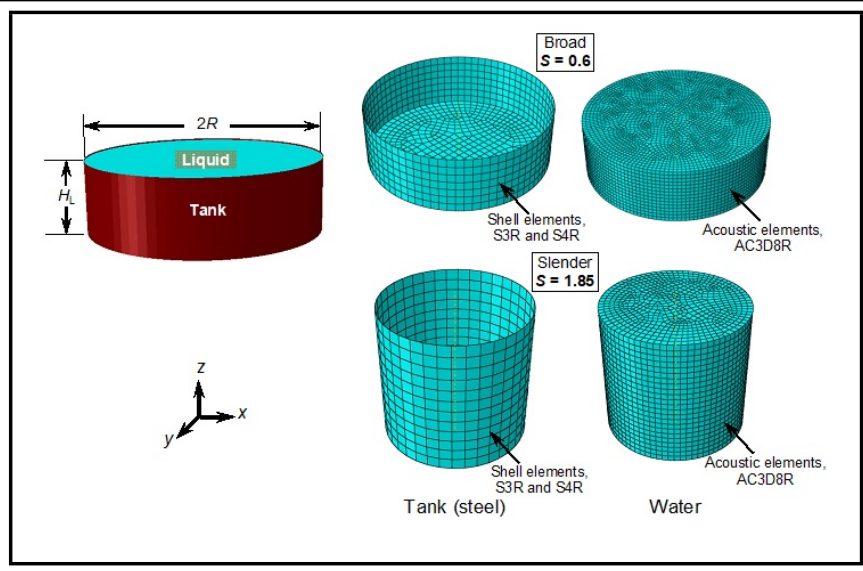

Figure 1. Coupled acoustic-structure finite element (FE) model of cylindrical liquid storage tank.

\subsection{Finite Element (FE) Modelling of the Tank}

Coupled acoustic-structural approach in the finite element method (FEM) is used for the seismic analysis of the liquid storage tank of radius, $R$ and liquid height, $H_{L}$ as shown in Fig. 1. In this approach, the water stored in the tank is modelled using acoustic eight-node 3-D continuum elements, AC3D8R, with hourglass control and reduced integration used for acoustic wave propagation, having only a single pressure degree-of-freedom at each node. ${ }^{64}$ The flexible tank wall is modelled using three-node triangular and four-node quadrilateral shell elements, S3R and S4R, respectively, with hourglass control and reduced integration, as shown in Fig. 1. The rigid tank wall is modelled using shell elements similar to flexible tank walls by assigning a large value of modulus of elasticity for the shell material which takes into consideration the rigidity of the tank wall. Thus, a modulus of elasticity twenty times greater than flexible shell material is used for modelling the relatively rigid behaviour of the tank.

The interaction between the tank wall and acoustic liquid elements is defined using a surface-based tie constraint, which allows both surfaces to remain in contact throughout the simulation process. This will set an appropriate fluid-structure boundary condition at the interface surrounding the liquid domain. At the interface of the liquid and the tank, the translation degree-of-freedom is tied between the nodes such that the acoustic nodes in contact with the shell elements have $x, y$, and $z$ translation degrees-of-freedom. ${ }^{1}$

In this FE model, boundary impedance interaction is defined at the free surface of the acoustic medium to model the sloshing behaviour considering the linearized wave condition. The boundary impedance defines the normal motion and the pressure of an acoustic medium at the boundary interface. The impedance boundary condition at any point along an acoustic medium is governed by

$$
\dot{u}_{\mathrm{out}}=\frac{1}{k_{1}} \dot{p}+\frac{1}{c_{1}} p
$$

where $\dot{u}_{\text {out }}$ is defined as the particle velocity in the outward normal direction of the acoustic medium, $p$ is the pressure in the acoustic medium, $\dot{p}$ is the time rate of change of the pressure in the acoustic medium, $1 / k_{1}$ is the proportionality constant between the displacement and the pressure in the normal direction to the surface, and $1 / c_{1}$ is the proportionality constant between the velocity and the pressure in normal direction to 
the surface. ${ }^{1}$ The sloshing of a free surface in the presence of the gravity is modelled by

$$
\frac{1}{k_{1}}=\frac{1}{\left(\rho_{L} g\right)} \quad \text { and } \quad \frac{1}{c_{1}}=0 ;
$$

where $g$ is the gravitational acceleration directed normal to the surface. If only the impulsive component of the liquid response is to be obtained, then the above boundary condition at the free surface of the liquid is to be replaced by zero acoustic pressure as given in Eq. (7). The convective response of the liquid is obtained by subtracting the impulsive response from the total response. In the present FE model, by using these boundary conditions at the free surface of the liquid, the convective and impulsive components of response are determined individually.

The dynamic response of the fixed-base liquid storage tank modelled using the coupled acoustic-structural (CAS) approach in the FEM subjected to ground acceleration, $\ddot{u}_{g}$ as an external base excitation is given as $8,53,58$

$$
\begin{aligned}
& {\left[\begin{array}{cc}
\boldsymbol{M}_{S} & 0 \\
\rho_{L} c_{0}^{2} \boldsymbol{Q}_{S A}^{T} & \boldsymbol{M}_{A}
\end{array}\right]\left\{\begin{array}{c}
\ddot{\boldsymbol{U}}_{S} \\
\ddot{\boldsymbol{P}}_{A}
\end{array}\right\}+\left[\begin{array}{cc}
\boldsymbol{C}_{S} & 0 \\
0 & \boldsymbol{C}_{A}
\end{array}\right]\left\{\begin{array}{c}
\dot{\boldsymbol{U}}_{S} \\
\dot{\boldsymbol{P}}_{A}
\end{array}\right\}+} \\
& {\left[\begin{array}{cc}
\boldsymbol{K}_{S} & -\boldsymbol{Q}_{S A} \\
0 & \boldsymbol{K}_{A}
\end{array}\right]\left\{\begin{array}{c}
\boldsymbol{U}_{S} \\
\boldsymbol{P}_{A}
\end{array}\right\}=-\left[\begin{array}{cc}
\boldsymbol{M}_{S} & 0 \\
0 & 0
\end{array}\right]\left\{\ddot{u}_{g}\right\}+} \\
& \left\{\begin{array}{c}
0 \\
\boldsymbol{F}_{q}
\end{array}\right\}
\end{aligned}
$$

where $U_{S}$ contain the nodal displacement values and over-dots indicate the derivative with respect to time, $t$. Moreover, $\boldsymbol{P}_{A}$ is the nodal pressure; $\boldsymbol{M}_{S}, \boldsymbol{C}_{S}$, and $\boldsymbol{K}_{S}$ are the structural mass, damping, and stiffness matrices of the structural domain, respectively. Further, $\boldsymbol{M}_{A}, \boldsymbol{C}_{A}$, and $\boldsymbol{K}_{A}$ are the mass of acoustic fluid domain, damping, and stiffness matrices, respectively; $c_{0}$ is the speed of sound, $c_{0}=\sqrt{K / \rho_{L}}$, where $K$ is the bulk modulus of liquid; ${ }^{68} \rho_{L}$ is the density of the fluid; $Q_{S A}$ spatial coupling matrix, $\mathrm{T}$ denotes transpose; and $F_{q}$ is the fluid force.

The fluid force on the structure is proportional to the pressure, resulting in a cross-coupling in the coupled stiffness matrix, while the structural force on the fluid is proportional to the acceleration, resulting in a cross-coupling matrix in the coupled mass matrix. For the practical calculation of the present coupled model, it is convenient that the acoustic and structural meshes are matching, i.e., the nodes of the structural and acoustic meshes at the fluid-structure coupling boundary coincide. If not, then the structural nodal displacement degrees-offreedom must be related to the acoustic nodal pressure degreesof-freedom along the fluid-structure coupling interface by using some geometrical transfer matrices.

The acceleration time history of an earthquake is applied as an input at the base of the tank. In case of the tank subjected to bi-directional components of an earthquake, acceleration time histories are simultaneously applied in both $x$ - and $y$-axes at the tank base.

For the time domain analysis, the dynamic implicit integration technique is adopted to obtain the seismic responses of the 3-D rigid and flexible tanks. An implicit method based on a Hilber-Hughes-Taylor (HHT) operator is used to perform the analysis in the Abaqus FE software, which is an extended general direct integration method from the trapezoidal rule. ${ }^{1}$

The acoustic pressures are measured at the two extreme nodes from the centre of the tank at the top surface of the liquid along both the $x$-axis $\left(\theta=0^{\circ}\right)$ and $y$-axis $\left(\theta=90^{\circ}\right)$, and

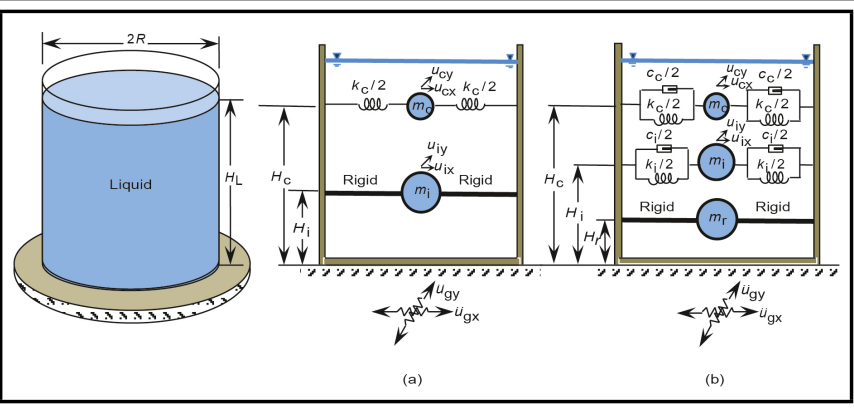

Figure 2. Lumped-mass model for (a) rigid and (b) flexible cylindrical fixed-base tanks.

the corresponding sloshing wave heights $h=p / \rho_{L} g$ ) are determined, where $\theta$ is the circumferential angle measured with respect to the $x$-axis. The base shear along the $x$-axis $\left(\theta=0^{\circ}\right)$ and $y$-axis $\left(\theta=90^{\circ}\right)$ is the sum of shear force components in the respective direction in the bottom elements of the tank wall along the circumference of the tank, where maximum shear stresses are developed. The hydrodynamic pressure developed along the liquid height is measured at each extreme node from the centre of the tank, along the height of the liquid in the acoustic elements. The maximum hydrodynamic pressure developed in the acoustic elements are measured along the $x$-axis $\left(\theta=0^{\circ}\right)$ and $y$-axis $\left(\theta=90^{\circ}\right)$.

\subsection{Lumped-mass/Analytical Model}

A two-lumped-mass model was proposed by Housner for the rigid cylindrical tank as shown in Fig. $2 \mathrm{a}^{30}$ In this model, the upper liquid mass is indicated by the convective mass $\left(m_{c}\right)$ and the lower liquid mass is indicated by the impulsive mass $\left(m_{i}\right)$ which is in rigid contact with the tank wall. As per the assumption that the tank moves as a rigid body, with the bottom and walls undergoing the same acceleration, the impulsive mass exerts a maximum horizontal force directly proportional to the maximum acceleration of the tank base. The acceleration also induces oscillation of the liquid mass, causing additional dynamic pressure on the tank wall, in which a certain portion of the liquid mass is flexibly connected to the tank wall. In this model, the convective mass of the liquid is considered to be connected to the solid tank wall with stiffness $\left(k_{c}\right)$ at a height, $H_{c}$ and the impulsive mass is connected rigidly to the tank wall at a height, $H_{i}$.

An analytical approach based on a three-lumped-mass model was proposed by Haroun and Housner, which is widely used for the dynamic analysis of the flexible cylindrical ground-supported tank, including contemporary codes. ${ }^{25,26} \mathrm{In}$ this model, the liquid in the tank is lumped into three masses as shown in Fig. $2 \mathrm{~b}$. The top liquid, which mainly causes the sloshing phenomenon, is called the convective mass $\left(m_{c}\right)$; the middle portion of the liquid which accelerates along with the tank is called the impulsive mass $\left(m_{i}\right)$; and the base liquid that moves rigidly along with the tank wall is called the rigid mass $\left(m_{r}\right)$. These masses are lumped at heights $H_{c}, H_{i}$, and $H_{r}$, respectively, from the bottom of the tank. The convective and impulsive masses are connected to the tank wall by corresponding equivalent springs having stiffness $k_{c}$ at a height, $H_{c}$; and $k_{i}$ at a height, $H_{i}$, respectively. And the damping constants of the convective and impulsive masses are $c_{c}$ and $c_{i}$, respectively. The effective masses in terms of the liquid mass in the cylindrical tank are given in graphical form by Haroun. ${ }^{24}$ The maximum sloshing displacement of the top liquid surface 
is given by Haroun, ${ }^{24}$ which is also recommended by the $\mathrm{Eu}-$ rocode $8^{13}$ as

$$
h=0.84 \frac{R A_{c}}{g}
$$

where $A_{c}=\omega_{c}^{2} u_{c}$ is the convective pseudo-acceleration, $\omega_{c}$ and $u_{c}$ are the frequency and displacement of the convective mass, respectively.

\section{VALIDATION OF THE FE MODEL}

The accuracy of the results obtained from the present FE model of the tank has been ensured by comparing it with that reported in the literature. The impulsive hydrodynamic pressures in the broad and slender rigid tanks under earthquake ground motion using the FE model are compared with the analytical solution proposed by Housner ${ }^{29}$ and Haroun and Housner. ${ }^{26}$ The geometrical dimensions of the broad and slender cylindrical tanks are given in Table 1 . The aspect ratio is defined as $S=H_{L} / R$, i.e. ratio of the liquid height $\left(H_{L}\right)$ to radius $R$ of the tank. The parameters used to model the steel tank and water contained in the tank are given in Table 2 . The tank is assumed to have a rigid wall, fixed condition at the base, and the tank floor is fully anchored to the rigid ground such that no sliding or uplift occurs. To facilitate the comparison, zero damping is assumed for the tank. The tank is subjected to the horizontal component of the Kobe, 1995 earthquake with peak ground acceleration (PGA) of $0.834 \mathrm{~g}$. The analytical impulsive hydrodynamic pressure, $p_{i}$ for a rigid cylindrical tank is given as

$$
p_{i}\left(\frac{r}{R}, \frac{z}{H_{L}}, \theta, t\right)=C_{i}\left(\frac{r}{R}, \frac{z}{H_{L}}\right) \rho_{L} H_{L} \cos (\theta) \ddot{u}_{g}(t) ;
$$

where $\ddot{u}_{g}(t)$ is the ground acceleration, and $t$ is time. The function, $C_{i}$ is given as

$$
\begin{aligned}
& C_{i}\left(\frac{r}{R}, \frac{z}{H_{L}}\right)= \\
& 2 \sum_{n=0}^{\infty}\left[\frac{(-1)^{n}}{I_{1}^{\prime}\left(\frac{\nu_{n}}{H_{L} / R}\right) \nu_{n}^{2}}\right] \cos \left(\nu_{n} z / H_{L}\right) I_{1}\left(\nu_{n} r / H_{L}\right) ;
\end{aligned}
$$

where $\nu_{n}=\frac{2 n+1}{2} \pi, I_{1}(\cdot)$ and $I_{1}^{\prime}(\cdot)$ denote the modified Bessel function of first order and its derivative. The first fifteen terms of the series, $n=0$ to 15 are used for calculating the hydrodynamic pressure, which gives sufficient accuracy for calculating the impulsive hydrodynamic pressure. The same study is also adopted for the mesh convergence to decide the size of the FE mesh which yields accurate results in the present numerical modelling approach. Figure 3 shows the comparison of the impulsive hydrodynamic pressure distribution along the liquid height in the broad and slender rigid tanks, using the present FE model and the analytical method. The impulsive pressure time history at $r=R, \theta=0, z=0$ are also shown in Fig. 3 for the broad and slender rigid tanks under the Kobe, 1995 earthquake. The impulsive hydrodynamic pressure is obtained at the bottom of the tank, adjacent to the wall $(r=R, \theta=0$, $z=0$ ) through the analytical and FE approaches and are given in Table 3 for various mesh sizes. From the FE mesh convergence study, $0.8 \mathrm{~m} \times 0.8 \mathrm{~m}$ size of the FE mesh is adopted in the present study for the broad and tanks, which yields close
Table 1. Geometrical dimensionsofcylindrical tank.

\begin{tabular}{|c|c|c|c|c||}
\hline Tank & $\begin{array}{c}\text { Aspect ratio, } \\
\left(S=H_{L} / R\right)\end{array}$ & $\begin{array}{c}\text { Height, } \\
\text { of water, } \\
H_{L}(\mathrm{~m})\end{array}$ & $\begin{array}{c}\text { Radius, } \\
\text { of tank, } \\
R(\mathrm{~m})\end{array}$ & $\begin{array}{c}\text { Height } \\
\text { of tank, } \\
H(\mathrm{~m})\end{array}$ \\
\hline Broad & 0.6 & 14.6 & 24.33 & 15.10 \\
\hline Slender & 1.85 & 11.3 & 6.10 & 11.80 \\
\hline
\end{tabular}

Table 2. Parameters of cylindricaltank and water.

\begin{tabular}{||c|c|}
\hline Tank (steel) & Water \\
\hline Density, $\rho_{s}=7,900 \mathrm{~kg} / \mathrm{m}^{3}$ & Density, $\rho_{w}=1,000 \mathrm{~kg} / \mathrm{m}^{3}$ \\
Modulus of elasticity, $E_{s}=200 \mathrm{GPa}$ & Bulk modulus, \\
Poisson's ratio, $\nu=0.3$ & $K=2,250 \mathrm{MPa}-$ \\
\hline
\end{tabular}
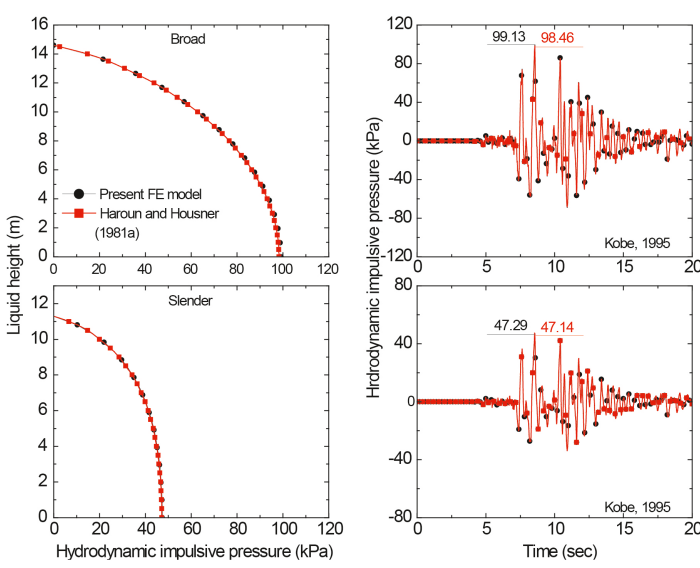

Figure 3. Hydrodynamic impulsive pressure distribution and time history at $(r=R, \theta=0, z=0$ in broad and slender rigid tanks subjected to Kobe, 1995 earthquake.

results as compared to the analytical results. Insignificant effect on the response calculations is observed with further refinement in the FE mesh.

The sloshing displacement is also studied for the present coupled acoustic-structural FE model and verified with the boundary element method (BEM) and experimental work reported by Chen et al. ${ }^{9}$ A rigid cylindrical tank having geometrical dimensions, such as radius, $R=30 \mathrm{~cm}$ and water height, $H_{L}=10 \mathrm{~cm}$, are considered for this study. The assumed harmonic ground displacement, $u_{g}=F_{f} \sin \omega_{f} t$, where $F_{f}=0.005 \mathrm{~m}$ is the amplitude of displacement and $\omega_{f}$ is the forcing frequency, is applied at the base of the tank. The cylindrical tank is subjected to non-resonant forcing frequency, $\omega_{f}=5.16 \mathrm{rad} / \mathrm{sec}$.

Figure 4 shows a comparison of the sloshing displacement time history response for the cylindrical tank subjected to a non-resonant forcing frequency obtained from the present FE model and that was reported by Chen et al. numerically and experimentally. ${ }^{9}$ The sloshing displacement is measured at the extreme point of the top free surface of water along the direction of the applied ground motion. It is observed from the plots that maximum sloshing displacement predicted by the present FEM is $0.38 \mathrm{~cm}$ while that reported by Chen et al. based on the BEM and experimental works are $0.33 \mathrm{~cm}$ and $0.47 \mathrm{~cm}$, respectively. ${ }^{9}$ The percentage variations in predicting the sloshing displacement by the FEM compared with the BEM and experimental approaches by Chen et al. are of $9 \%$ and $30 \%$, respectively. ${ }^{9}$ Thus, it is confirmed that the coupled acousticstructural FE model results are in close agreement with the 
Table 3. FE mesh convergence study for rigid broad and slender tanks.

\begin{tabular}{|c|c|c|c|c|}
\hline \multirow{3}{*}{ Mesh size (m) } & \multicolumn{4}{|c|}{ Maximum impulsive hydrodynamic pressure in rigid tank $(\mathrm{kPa})$} \\
\hline & \multicolumn{2}{|r|}{ Broad tank } & \multicolumn{2}{|c|}{ Slender tank } \\
\hline & Present FE model & Haroun and Housner (1981a) & Present FE model & Haroun and Housner (1981a) \\
\hline $1.6 \times 1.6$ & 99.87 & \multirow{5}{*}{98.46} & 47.96 & \multirow{5}{*}{47.14} \\
\hline $1.4 \times 1.4$ & 99.71 & & 47.89 & \\
\hline $1.2 \times 1.2$ & 99.34 & & 47.66 & \\
\hline $1.0 \times 1.0$ & 99.18 & & 47.34 & \\
\hline $0.8 \times 0.8$ & 99.13 & & 47.29 & \\
\hline
\end{tabular}

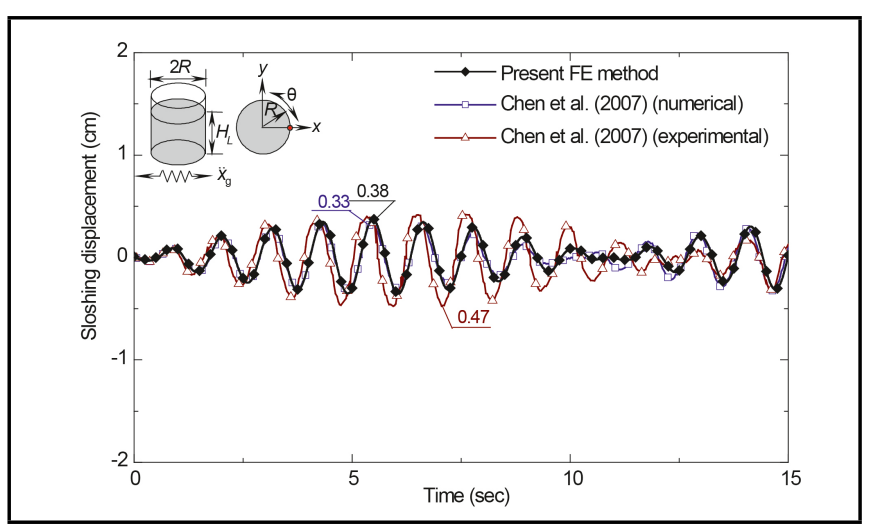

Figure 4. Sloshing displacement time history response of cylindrical tank.

BEM and experimental results; thereby, this verifies the validity of the present FE model.

\section{NUMERICAL STUDY}

In the present study, 3-D FE ground-supported rigid and flexible cylindrical tanks are investigated under unidirectional harmonic ground motions and horizontal bi-directional components of earthquake ground motions using the developed and validated models. The two aspect ratios, $S=0.6$ for the broad tank and $S=1.85$ for the slender tank, are considered, with the geometrical dimensions given in Table 1. The parameters used to define the steel tank and water are tabulated in Table 2. The ratio of the tank wall thickness to its radius, $t_{s} / R$ is taken as 0.004 for both the tanks. ${ }^{31}$ In the present numerical study, the structural damping of $2 \%$ is now used for the flexible steel tank.

\subsection{Response to Harmonic Ground Motions}

The broad and slender tanks subjected to unidirectional harmonic ground motion are investigated. The harmonic base acceleration applied to the tank is given as

$$
\ddot{u}_{g}=a_{0} \exp (i \omega t)
$$

where $a_{0}$ and $\omega$ are the amplitude and excitation frequency, respectively. ${ }^{7}$ For the present study, the amplitudes in the range of $0.15 \mathrm{~g}, 0.225 \mathrm{~g}, 0.3 \mathrm{~g}$, and $0.375 \mathrm{~g}$ and the excitation frequencies in the range of $1 \mathrm{~Hz}, 2 \mathrm{~Hz}$, and $3 \mathrm{~Hz}$ are considered, which fairly represent salient characteristics of typical earthquake ground motions. ${ }^{57}$

The sloshing displacement of liquid in the 3-D FE model of the tank is measured at the extreme top node from the centre of the tank in $x$-axis $\left(\theta=0^{\circ}\right)$ along the direction of excitation. Fig. 5 shows the time history responses of the sloshing displacement in the broad and slender flexible tanks obtained from the present FE model and compared with the three

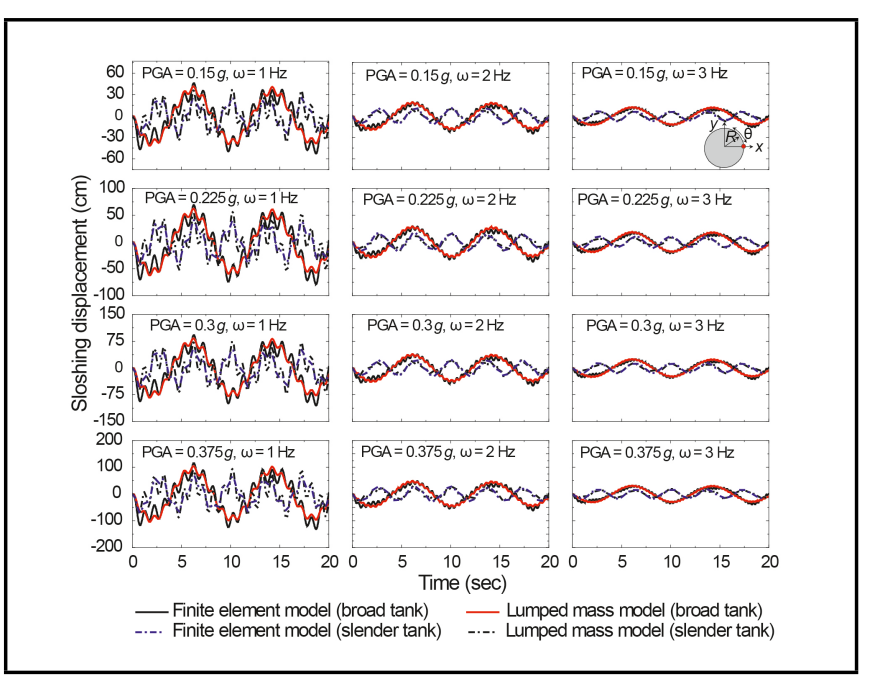

Figure 5. Sloshing response in broad and slender flexible cylindrical tank subjected to harmonic ground motions.

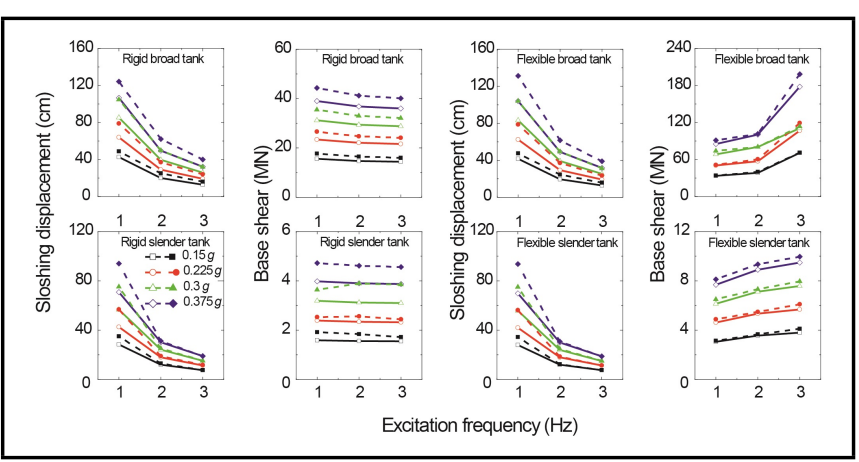

Figure 6. Effect of amplitude and excitation frequency of harmonic motion on rigid and flexible tanks.

lumped-mass model for unidirectional harmonic motion. Furthermore, Fig. 6 shows the effect of amplitude and excitation frequency on the sloshing and base shear responses in the rigid and flexible, broad and slender tanks, which are analysed using the two and three lumped-mass models, respectively and compared with the present FE model. It can be observed that the base shear developed in the rigid tank is less as compared to the flexible tank, as the latter takes the flexibility of the tank into account, wherein the impulsive component of the liquid becomes more prominent. Thus, in the design of the liquid storage tanks, it is crucial to account for the flexibility of the tank wall to ensure predicting correct design forces, which are otherwise underestimated by the two-parameter lumped-mass model.

The plots in Fig. 5 and 6 show that the sloshing displacement determined using the present FE model is increased by about 15 to $20 \%$ in comparison with that determined using the lumped-mass model. The difference in the results obtained 
from the FE and the lumped-mass models in sloshing response calculation is due to the assumption that in the lumped-mass models, only the fundamental sloshing frequency is considered in the analysis. The base shear calculated using the three lumped-mass model is almost the same as the base shear calculated using the FE model with a percentage increase of about 4 to $10 \%$. This increased base shear calculated through the FE approach helps in conservative design of the liquid storage tank.

The peak values of the sloshing displacement and base shear in the rigid and flexible as well as broad and slender tanks predicted using the present FE model are summarized in Table 4. The seismic response quantities are compared with the two and three lumped-mass models for the rigid and flexible tanks, respectively. Table 4 shows that the peak sloshing displacement and base shear increase with the amplitude of the ground motion. Thus, the peak ground acceleration (PGA) is an earthquake intensity measure in determining the design forces for the liquid storage tanks.

\subsection{Response to Bi-directional Components of Earthquakes}

Typically, the liquid storage tanks are analysed only for one significant component of the earthquake ground motion, ignoring the influence of the other component and the consequent interaction effects. Hence, the seismic response of the tanks subjected to the bi-directional components of earthquakes will be interesting to study. Therefore, the ground-supported cylindrical liquid storage tank is subjected to horizontal bi-directional components of real earthquake ground motion. The characteristics of the five real earthquakes considered in the present study are given in Table 5 along with their peak ground acceleration (PGA) in terms of $g$, in both $x$ - and $y$-axes.

The dynamic responses obtained from the present coupled acoustic-structural (CAS) approach in the FE model are compared to that with the lumped-mass model for the rigid and flexible tanks. The sloshing displacement is measured at the two extreme nodes (near the tank wall) from the centre of the tank in both $x$-axis $\left(\theta=0^{\circ}\right)$ and $y$-axis $\left(\theta=90^{\circ}\right)$ under the bi-directional components of the earthquakes. Fig. 7 shows the sloshing displacement time history responses for the broad and slender flexible tanks and compares them with the three lumped-mass model in both $x$-axis $\left(\theta=0^{\circ}\right)$ and $y$ axis $\left(\theta=90^{\circ}\right)$ for the Imperial Valley, 1940; Northridge (Sylmar station), 1994; and Kobe, 1995 earthquakes. Table 6a presents a comparison of the peak values of the sloshing displacement evaluated using the FE and lumped-mass models for the rigid and flexible broad tanks. Similarly, Table $6 \mathrm{~b}$ gives a comparison of the peak values of the responses for the rigid and flexible slender tanks. From the tabulated values, it is observed that the sloshing displacement is relatively insensitive to the flexibility of the tank and is nearly same in the rigid and flexible tanks. This is attributed to the fact that the oscillation of the liquid in the convective frequency is dominated by the natural frequencies much lower than those associated with the tank. The sloshing amplitude mainly depends on the tank geometry, liquid properties, liquid height in the tank, and nature of excitation. In the present study, the sloshing displacement is seen unusually to be more in the case of the slender tank as compared to the broad tank.

The tank wall thickness is designed based on the seismic base shear developed in the tank walls due to the hydrodynamic

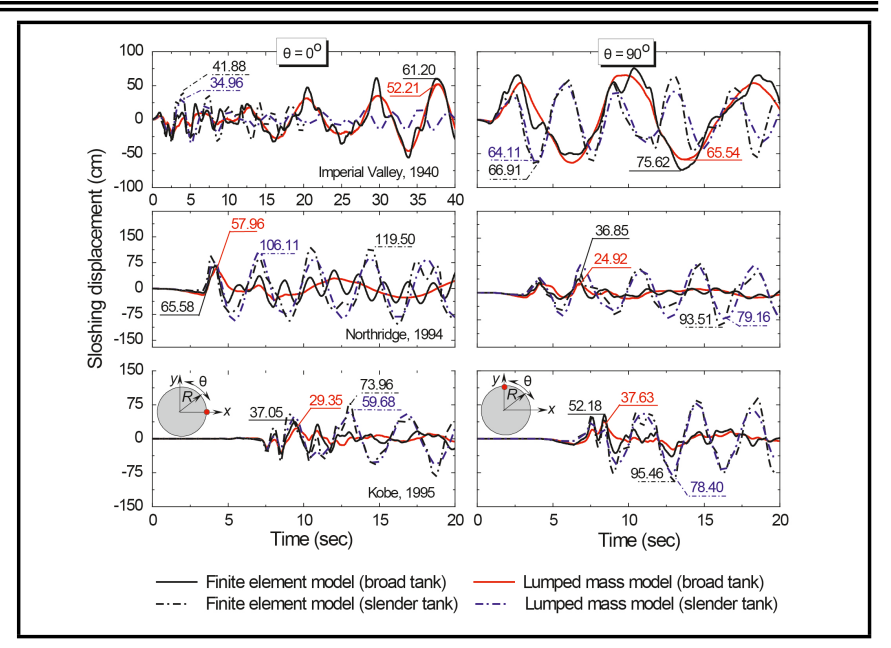

Figure 7. Sloshing displacement response in $x$-axis $\left(\theta=0^{\circ}\right)$ and $y$-axis $\left(\theta=90^{\circ}\right)$ in broad and slender flexible tanks under bi-directional components of earthquakes.

pressure induced by the liquid in the tank. The total base shear is the contribution from the impulsive and convective hydrodynamic pressure components in the liquid. The time history responses of the impulsive and convective components of the base shear (induced due to liquid) for the rigid and flexible broad tanks along $x$-axis $\left(\theta=0^{\circ}\right)$ and $y$-axis $\left(\theta=90^{\circ}\right)$ are calculated using the FE model and are plotted in Fig. 8. The impulsive and convective components of the base shear time history responses for the rigid and flexible slender tank using the FE model are shown in Fig. 9. It can be observed from Figs. 8 and 9 that the impulsive component has a more significant contribution in the total base shear developed in the tank than the convective component. This means sloshing induces relatively less tank wall base shear as compared to the base shear contributed by the impulsive component of the liquid in motion. The peak responses of the impulsive and convective components do not occur in the same phase or at the same instant of time. From Tables $6 \mathrm{a}$ and $6 \mathrm{~b}$, it is seen that the convective component is independent of the tank flexibility; however, the impulsive component is highly influenced by the flexibility in the tank wall. With the increased flexibility of the tank wall, the impulsive component of the base shear increases. In the present study, the base shear developed is lesser in the case of the slender tank in comparison with that in the broad tank.

The absolute maximum impulsive hydrodynamic pressure developed along the liquid height in the broad and slender tanks along $x$-axis $\left(\theta=0^{\circ}\right)$ and $y$-axis $\left(\theta=90^{\circ}\right)$ under bidirectional components of earthquake is shown in Fig. 10. The impulsive component has a more significant contribution in the total base shear developed in the tank wall as compared to the convective component; therefore, in the present study, impulsive hydrodynamic pressure is presented. The impulsive hydrodynamic pressure profiles are compared in the case of the rigid and flexible tanks subjected to bi-directional components of earthquake as shown in Table 7, using the present FE model and using Haroun and Housner's analytical approach. ${ }^{25}$ The effect of tank flexibility on the convective pressure is observed to be negligible; therefore, it is not shown in the plots. The impulsive hydrodynamic pressure has considerably amplified due to the tank flexibility. The distribution of the impulsive pressure has significantly differed due to the flexibility of the tank. In the case of the rigid tank, the maximum impulsive pressure is developed at the base of the tank, while in the flex- 
A. Rawat, et al.: SEISMIC ANALYSIS OF STEEL CYLINDRICAL LIQUID STORAGE TANK USING COUPLED ACOUSTIC-STRUCTURAL...

Table 4. Peak sloshing displacement and base shear in cylindrical tank subjected to harmonic ground motion.

\begin{tabular}{|c|c|c|c|c|c|c|c|c|c|c|}
\hline \multirow{3}{*}{$\begin{array}{l}\text { Aspect } \\
\text { ratio }(S)\end{array}$} & \multirow{3}{*}{$\begin{array}{l}\text { PGA } \\
(\mathrm{g})\end{array}$} & \multirow{3}{*}{$\begin{array}{c}\text { External } \\
\text { frequency }(\mathrm{Hz})\end{array}$} & \multicolumn{4}{|c|}{ Rigid tank } & \multicolumn{4}{|c|}{ Flexible tank } \\
\hline & & & \multicolumn{2}{|c|}{$\begin{array}{c}\text { Peak sloshing } \\
\text { displacement }(\mathrm{cm})\end{array}$} & \multicolumn{2}{|c|}{$\begin{array}{c}\text { Peak base } \\
\text { shear }(\mathrm{MN})\end{array}$} & \multicolumn{2}{|c|}{$\begin{array}{c}\text { Peak sloshing } \\
\text { displacement }(\mathrm{cm})\end{array}$} & \multicolumn{2}{|c|}{$\begin{array}{c}\text { Peak base } \\
\text { shear }(\mathrm{MN})\end{array}$} \\
\hline & & & $\begin{array}{c}2 \text { lumped-mass } \\
\text { model }\end{array}$ & $\begin{array}{c}\text { FE } \\
\text { model }\end{array}$ & $\begin{array}{c}2 \text { lumped-mass } \\
\text { model }\end{array}$ & $\begin{array}{c}\mathrm{FE} \\
\text { model }\end{array}$ & $\begin{array}{c}3 \text { lumped-mass } \\
\text { model }\end{array}$ & $\begin{array}{c}\mathrm{FE} \\
\text { model }\end{array}$ & $\begin{array}{c}3 \text { lumped-mass } \\
\text { model }\end{array}$ & $\begin{array}{c}\mathrm{FE} \\
\text { model }\end{array}$ \\
\hline \multirow{10}{*}{0.6} & \multirow[b]{2}{*}{0.15} & 1 & 42.69 & 48.86 & 15.58 & 17.74 & 41.60 & 47.49 & 33.71 & 34.15 \\
\hline & & 2 & 19.87 & 24.96 & 14.70 & 16.49 & 19.60 & 24.65 & 38.25 & 40.19 \\
\hline & \multirow{3}{*}{0.225} & 1 & 64.04 & 78.98 & 23.37 & 26.61 & 62.41 & 78.74 & 50.57 & 51.22 \\
\hline & & 2 & 29.08 & 37.05 & 22.06 & 24.74 & 29.40 & 36.98 & 57.38 & 60.29 \\
\hline & & 3 & 19.31 & 23.95 & 21.58 & 24.07 & 19.09 & 23.42 & 106.69 & 119.10 \\
\hline & \multirow{3}{*}{0.3} & 1 & 85.39 & 104.86 & 31.17 & 35.48 & 83.21 & 104.02 & 68.3 & 74.17 \\
\hline & & 2 & 39.74 & 49.94 & 29.41 & 32.99 & 39.20 & 49.31 & 80.33 & 80.39 \\
\hline & & 3 & 25.75 & 31.89 & 28.78 & 32.09 & 25.46 & 31.23 & 110.96 & 113.43 \\
\hline & \multirow{2}{*}{0.375} & 1 & 106.74 & 124.18 & 38.96 & 44.35 & 104.01 & 131.23 & 85.37 & 91.35 \\
\hline & & 3 & 32.19 & 39.92 & 35.97 & 40.12 & 31.83 & 39.04 & 177.81 & 198.50 \\
\hline \multirow{12}{*}{1.85} & \multirow{3}{*}{0.15} & 1 & 28.35 & 34.92 & 1.59 & 1.92 & 27.95 & 34.47 & 3.07 & 3.15 \\
\hline & & 2 & 12.06 & 13.02 & 1.56 & 1.84 & 11.96 & 12.36 & 3.56 & 3.66 \\
\hline & & 3 & 7.59 & 7.61 & 1.55 & 1.72 & 7.54 & 7.55 & 3.80 & 4.13 \\
\hline & \multirow{3}{*}{0.225} & 1 & 42.52 & 56.87 & 2.39 & 2.53 & 41.91 & 56.20 & 4.62 & 4.88 \\
\hline & & 2 & 18.10 & 18.92 & 2.34 & 2.56 & 17.94 & 18.54 & 5.34 & 5.49 \\
\hline & & 3 & 11.39 & 11.71 & 2.32 & 2.44 & 11.31 & 11.33 & 5.69 & 6.11 \\
\hline & \multirow{3}{*}{0.3} & 1 & 56.70 & 75.14 & 3.19 & 3.24 & 55.89 & 74.94 & 6.15 & 6.51 \\
\hline & & 2 & 24.13 & 25.16 & 3.12 & 3.89 & 23.93 & 24.72 & 7.12 & 7.33 \\
\hline & & 3 & 15.19 & 15.26 & 3.10 & 3.85 & 15.08 & 15.11 & 7.59 & 7.96 \\
\hline & \multirow{3}{*}{0.375} & 1 & 70.88 & 93.91 & 3.98 & 4.72 & 69.86 & 93.68 & 7.69 & 8.13 \\
\hline & & 2 & 30.16 & 31.15 & 3.90 & 4.61 & 29.91 & 30.90 & 8.90 & 9.35 \\
\hline & & 3 & 18.98 & 19.08 & 3.87 & 4.56 & 18.85 & 18.89 & 9.49 & 9.97 \\
\hline
\end{tabular}

Table 5. Characteristics of the five earthquake ground motions.

\begin{tabular}{|c|c|c|c|}
\hline Earthquake event & Recording station & $x$-component PGA $(g)$ & $y$-component PGA $(g)$ \\
\hline Imperial Valley $19^{\text {th }}$ May, 1940, California & El Centro & 0.348 & 0.214 \\
\hline Loma Prieta $18^{\text {th }}$ October, 1989, California & Los Gatos Presentation (LGP) Center & 0.569 & 0.607 \\
\hline Northridge $(\mathrm{NH}) 17^{\text {th }}$ January, 1994, California & Newhall (NH) Fire Station & 0.589 & 0.583 \\
\hline Northridge $17^{\text {th }}$ January, 1994, California & Sylmar Converter Center & 0.842 & 0.604 \\
\hline Kobe $17^{\text {th }}$ January, 1995, Japan & Japan Meteorological Agency (JMA) & 0.834 \\
\hline
\end{tabular}

ible tank it is nearly at one-third height from the base of the tank. Such an increase in the base shear developed and change in point of application of the peak seismic force are important considerations in the safe design of the liquid storage tanks.

Figure 11 shows the contour plots of von Mises stress developed in the wall of the flexible broad and slender tanks when subjected to the Imperial Valley, 1940 earthquake. The contour has been plotted at the time instant when maximum stresses have been developed. It can be observed that the maximum stress is developed at about one-third height from the base of the tank, where the maximum hydrodynamic pressure has been developed. The determination of stress induced in the tank wall material is important in order to design and check against the tank wall buckling and failing during an earthquake event.

\section{CONCLUSIONS}

Seismic analyses of 3-D ground-supported rigid and flexible cylindrical liquid storage tanks subjected to unidirectional harmonic ground motion and horizontal bi-directional components of the real earthquake are investigated using the coupled acoustic-structural finite element (FE) model. The results obtained from the FE model are compared with the contemporary lumped-mass models used in the codes for design. The two aspect ratios for the broad and slender tanks are considered for the study while determining the dynamic response quantities such as sloshing displacement, base shear, and hydrodynamic impulsive pressure. The following conclusions are drawn from the present study:

1. Using the coupled acoustic-structural (CAS) approach in the finite element (FE) method for seismic analysis of ground-supported liquid storage tanks, both convective and impulsive components can be evaluated separately by using the appropriate boundary conditions at the top free liquid surface.

2. The results obtained from the 3-D FE model and lumpedmass model are in close agreement. The average percentage difference in the 3-D FE and lumped-mass models for maximum sloshing displacement prediction is about 15 to $20 \%$, and that for the base shear is about 4 to $10 \%$, in the case of the unidirectional harmonic ground motions. The difference in the sloshing response is attributed to the assumption of considering only the first sloshing frequency in the lumped-mass model.

3. It is concluded that the sloshing displacement is insensitive to the flexibility of the tank and is nearly same in the rigid and flexible tanks. 
Table 6. Comparison of peak responses in rigid and flexible broad cylindrical tanks subjected to bi-directional components of earthquake.

(a)

\begin{tabular}{|c|c|c|c|c|c|c|c|}
\hline \multirow{2}{*}{ Aspect ratio (S) } & \multirow{2}{*}{$\begin{array}{l}\text { Earthquake } \\
\text { excitation }\end{array}$} & \multirow{2}{*}{ Tank } & \multirow{2}{*}{$\begin{array}{l}\text { Peak response } \\
\text { quantities }\end{array}$} & \multicolumn{2}{|c|}{ Along $x$-axis $\left(\theta=0^{\circ}\right)$} & \multicolumn{2}{|c|}{ Along $y$-axis $\left(\theta=90^{\circ}\right)$} \\
\hline & & & & $\begin{array}{c}\text { \# Lumped-mass } \\
\text { model }\end{array}$ & FE model & $\begin{array}{c}\text { \# Lumped-mass } \\
\text { model }\end{array}$ & FE model \\
\hline \multirow{30}{*}{0.6} & \multirow{6}{*}{ Imperial Valley, 1940} & \multirow{3}{*}{ Rigid } & Sloshing $(\mathrm{cm})$ & 55.18 & 63.87 & 67.32 & 76.56 \\
\hline & & & $\mathrm{I}^{*}$ base shear $(\mathrm{MN})$ & 32.00 & 35.20 & 19.60 & 21.61 \\
\hline & & & $\mathrm{C}^{*}$ base shear $(\mathrm{MN})$ & 3.06 & 4.34 & 3.74 & 5.30 \\
\hline & & \multirow{3}{*}{ Flexible } & Sloshing $(\mathrm{cm})$ & 52.21 & 61.20 & 65.54 & 75.62 \\
\hline & & & $\mathrm{I}^{*}$ base shear $(\mathrm{MN})$ & 126.37 & 127.08 & 95.02 & 96.05 \\
\hline & & & $\mathrm{C}^{*}$ base shear $(\mathrm{MN})$ & 4.12 & 5.06 & 5.17 & 6.01 \\
\hline & \multirow{6}{*}{ Loma Prieta, 1989} & \multirow{3}{*}{ Rigid } & Sloshing $(\mathrm{cm})$ & 68.55 & 76.04 & 21.60 & 26.30 \\
\hline & & & I base shear (MN) & 50.91 & 56.13 & 40.23 & 44.29 \\
\hline & & & C base shear (MN) & 3.81 & 5.40 & 1.20 & 1.70 \\
\hline & & \multirow{3}{*}{ Flexible } & Sloshing $(\mathrm{cm})$ & 68.30 & 76.11 & 21.11 & 25.92 \\
\hline & & & $\mathrm{I}^{*}$ base shear $(\mathrm{MN})$ & 211.51 & 214.67 & 165.20 & 171.39 \\
\hline & & & $\mathrm{C}^{*}$ base shear (MN) & 5.39 & 6.12 & 1.70 & 1.84 \\
\hline & \multirow{6}{*}{ Northridge (NH), 1994} & \multirow{3}{*}{ Rigid } & Sloshing $(\mathrm{cm})$ & 64.03 & 72.93 & 35.85 & 45.32 \\
\hline & & & I base shear (MN) & 54.10 & 59.54 & 53.47 & 58.86 \\
\hline & & & $\mathrm{C}$ base shear (MN) & 3.56 & 5.04 & 1.93 & 2.82 \\
\hline & & \multirow{3}{*}{ Flexible } & Sloshing $(\mathrm{cm})$ & 63.65 & 87.47 & 34.94 & 43.15 \\
\hline & & & $\mathrm{I}^{*}$ base shear $(\mathrm{MN})$ & 304.33 & 314.35 & 339.71 & 348.19 \\
\hline & & & $\mathrm{C}^{*}$ base shear $(\mathrm{MN})$ & 5.02 & 6.09 & 2.82 & 3.05 \\
\hline & \multirow{6}{*}{ Northridge, 1994} & \multirow{3}{*}{ Rigid } & Sloshing $(\mathrm{cm})$ & 58.05 & 66.04 & 24.99 & 36.17 \\
\hline & & & I base shear (MN) & 77.30 & 85.09 & 55.40 & 60.99 \\
\hline & & & C base shear (MN) & 3.23 & 4.57 & 1.39 & 1.97 \\
\hline & & \multirow{3}{*}{ Flexible } & Sloshing $(\mathrm{cm})$ & 57.96 & 65.58 & 24.92 & 36.85 \\
\hline & & & $\mathrm{I}^{*}$ base shear $(\mathrm{MN})$ & 272.72 & 274.92 & 143.8 & 145.43 \\
\hline & & & $\mathrm{C}^{*}$ base shear $(\mathrm{MN})$ & 4.57 & 5.62 & 1.96 & 2.18 \\
\hline & \multirow{6}{*}{ Kobe, 1995} & \multirow{3}{*}{ Rigid } & Sloshing $(\mathrm{cm})$ & 29.45 & 38.01 & 37.78 & 54.05 \\
\hline & & & I base shear (MN) & 76.47 & 84.20 & 57.70 & 63.52 \\
\hline & & & C base shear $(\mathrm{MN})$ & 1.64 & 2.32 & 2.10 & 2.98 \\
\hline & & \multirow{3}{*}{ Flexible } & Sloshing $(\mathrm{cm})$ & 29.35 & 37.05 & 37.63 & 52.18 \\
\hline & & & $\mathrm{I}^{*}$ base shear $(\mathrm{MN})$ & 256.01 & 258.32 & 171.01 & 173.21 \\
\hline & & & $\mathrm{C}^{*}$ base shear $(\mathrm{MN})$ & 2.32 & 2.98 & 2.97 & 3.18 \\
\hline
\end{tabular}

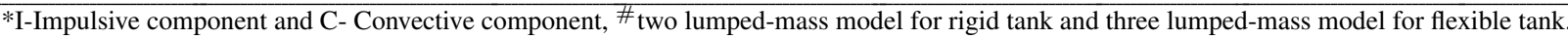

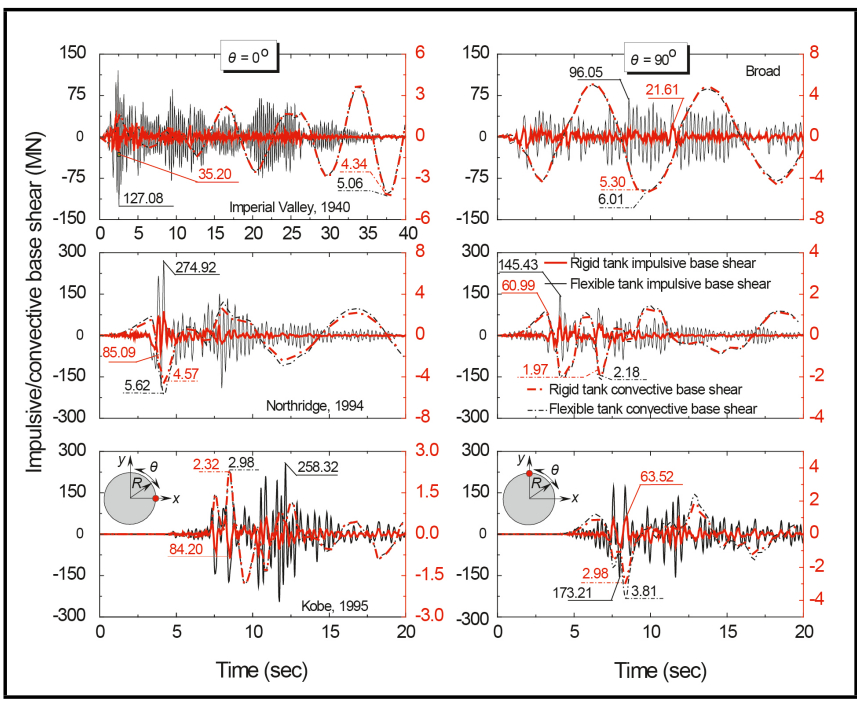

Figure 8. Impulsive and convective base shear time history responses in $x$-axis $\left(\theta=0^{\circ}\right)$ and $y$-axis $\left(\theta=90^{\circ}\right)$ in broad tank subjected to bi-directional components of earthquakes.

4. The total base shear is the contribution from the convective and impulsive components. It is concluded that the impulsive component has a more significant contribution in the total base shear developed in the tank than the convective component. The convective component is inde-

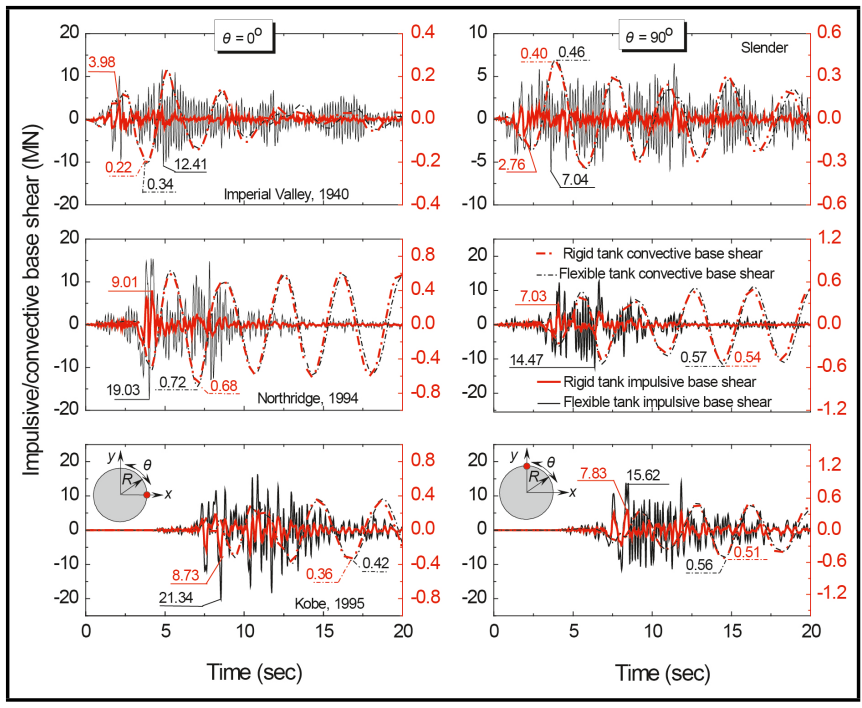

Figure 9. Impulsive and convective base shear time history responses in $x$-axis $\left(\theta=0^{\circ}\right)$ and $y$-axis $\left(\theta=90^{\circ}\right)$ in slender tank subjected to bi-directional components of earthquakes.

pendent of the tank flexibility as compared to the impulsive component. Here, the base shear developed is less in the case of the slender tank in comparison with the broad tank. 
A. Rawat, et al.: SEISMIC ANALYSIS OF STEEL CYLINDRICAL LIQUID STORAGE TANK USING COUPLED ACOUSTIC-STRUCTURAL...

Table 6 (continued). Comparison of peak responses in rigid and flexible broad cylindrical tanks subjected to bi-directional components of earthquake.

(b)

\begin{tabular}{|c|c|c|c|c|c|c|c|}
\hline \multirow{2}{*}{ Aspect ratio (S) } & \multirow{2}{*}{$\begin{array}{l}\text { Earthquake } \\
\text { excitation }\end{array}$} & \multirow{2}{*}{ Tank } & \multirow{2}{*}{$\begin{array}{c}\text { Peak response } \\
\text { quantities }\end{array}$} & \multicolumn{2}{|c|}{ Along $x$-axis $\left(\theta=0^{\circ}\right)$} & \multicolumn{2}{|c|}{ Along $y$-axis $\left(\theta=90^{\circ}\right)$} \\
\hline & & & & $\begin{array}{c}\text { \# Lumped-mass } \\
\text { model }\end{array}$ & FE model & $\begin{array}{c}\text { \# Lumped-mass } \\
\text { model }\end{array}$ & FE model \\
\hline \multirow{30}{*}{0.6} & \multirow{6}{*}{ Imperial Valley, 1940} & \multirow{3}{*}{ Rigid } & Sloshing $(\mathrm{cm})$ & 37.02 & 41.76 & 64.80 & 66.31 \\
\hline & & & I base shear (MN) & 3.54 & 3.98 & 2.18 & 2.76 \\
\hline & & & $\mathrm{C}$ base shear $(\mathrm{MN})$ & 0.16 & 0.22 & 0.28 & 0.40 \\
\hline & & \multirow{3}{*}{ Flexible } & Sloshing $(\mathrm{cm})$ & 34.96 & 41.88 & 64.11 & 66.91 \\
\hline & & & $\mathrm{I}^{*}$ base shear $(\mathrm{MN})$ & 11.57 & 12.41 & 6.53 & 7.04 \\
\hline & & & $\mathrm{C}^{*}$ base shear $(\mathrm{MN})$ & 0.22 & 0.34 & 0.41 & 0.46 \\
\hline & \multirow{6}{*}{ Loma Prieta, 1989} & \multirow{3}{*}{ Rigid } & Sloshing $(\mathrm{cm})$ & 227.98 & 223.96 & 56.96 & 62.81 \\
\hline & & & I base shear (MN) & 5.28 & 5.80 & 5.33 & 6.18 \\
\hline & & & C base shear (MN) & 0.99 & 1.40 & 0.24 & 0.35 \\
\hline & & \multirow{3}{*}{ Flexible } & Sloshing $(\mathrm{cm})$ & 217.51 & 221.80 & 54.70 & 60.08 \\
\hline & & & I* base shear (MN) & 24.12 & 26.91 & 17.16 & 19.01 \\
\hline & & & $\mathrm{C}^{*}$ base shear $(\mathrm{MN})$ & 1.41 & 1.58 & 0.35 & 0.41 \\
\hline & \multirow{6}{*}{ Northridge (NH), 1994} & \multirow{3}{*}{ Rigid } & Sloshing $(\mathrm{cm})$ & 131.79 & 139.13 & 84.71 & 93.48 \\
\hline & & & I base shear (MN) & 5.47 & 6.00 & 5.41 & 5.93 \\
\hline & & & $\mathrm{C}$ base shear $(\mathrm{MN})$ & 0.57 & 0.81 & 0.36 & 0.52 \\
\hline & & \multirow{3}{*}{ Flexible } & Sloshing $(\mathrm{cm})$ & 116.20 & 138.98 & 76.48 & 92.55 \\
\hline & & & I* base shear $(\mathrm{MN})$ & 17.52 & 19.91 & 8.21 & 9.14 \\
\hline & & & $\mathrm{C}^{*}$ base shear $(\mathrm{MN})$ & 0.71 & 0.83 & 0.47 & 0.52 \\
\hline & \multirow{6}{*}{ Northridge, 1994} & \multirow{3}{*}{ Rigid } & Sloshing $(\mathrm{cm})$ & 111.18 & 121.34 & 87.98 & 94.86 \\
\hline & & & I base shear (MN) & 8.58 & 9.01 & 6.14 & 7.03 \\
\hline & & & $\mathrm{C}$ base shear $(\mathrm{MN})$ & 0.48 & 0.68 & 0.38 & 0.54 \\
\hline & & \multirow{3}{*}{ Flexible } & Sloshing $(\mathrm{cm})$ & 106.11 & 119.50 & 79.16 & 93.51 \\
\hline & & & $\mathrm{I}^{*}$ base shear $(\mathrm{MN})$ & 17.42 & 19.03 & 12.78 & 14.47 \\
\hline & & & $\mathrm{C}^{*}$ base shear $(\mathrm{MN})$ & 0.69 & 0.72 & 0.52 & 0.57 \\
\hline & \multirow{6}{*}{ Kobe, 1995} & \multirow{3}{*}{ Rigid } & Sloshing $(\mathrm{cm})$ & 59.85 & 74.10 & 83.67 & 94.72 \\
\hline & & & I base shear (MN) & 8.48 & 8.73 & 6.40 & 7.83 \\
\hline & & & C base shear (MN) & 0.26 & 0.36 & 0.36 & 0.51 \\
\hline & & \multirow{3}{*}{ Flexible } & Sloshing $(\mathrm{cm})$ & 59.68 & 73.96 & 78.40 & 95.46 \\
\hline & & & $\mathrm{I}^{*}$ base shear $(\mathrm{MN})$ & 20.21 & 21.34 & 14.07 & 15.62 \\
\hline & & & $\mathrm{C}^{*}$ base shear $(\mathrm{MN})$ & 0.38 & 0.42 & 0.51 & 0.56 \\
\hline
\end{tabular}

*I-Impulsive component and C- Convective component, \# two lumped-mass model for rigid tank and three lumped-mass model for flexible tank.

Table 7. Peak impulsive hydrodynamic pressure in rigid and flexible tanks subjected to bi-directional components of earthquakes.

\begin{tabular}{|c|c|c|c|c|c|c|c|}
\hline \multirow{2}{*}{ Aspect ratio $(\mathrm{S})$} & \multirow{2}{*}{ Earthquake excitation } & \multicolumn{3}{|c|}{ Along $x$-axis $\left(\theta=0^{\circ}\right)$} & \multicolumn{3}{|c|}{ Along $y$-axis $\left(\theta=90^{\circ}\right)$} \\
\hline & & $\begin{array}{c}\text { Haroun } \\
\text { and Housner (1981a) } \\
(\mathrm{kPa})\end{array}$ & $\begin{array}{l}\text { Rigid tank } \\
(\mathrm{kPa})\end{array}$ & $\begin{array}{c}\text { Flexible tank } \\
(\mathrm{kPa})\end{array}$ & $\begin{array}{c}\text { Haroun } \\
\text { and Housner (1981a) } \\
(\mathrm{kPa})\end{array}$ & $\begin{array}{l}\text { Rigid tank } \\
\quad(\mathrm{kPa})\end{array}$ & $\begin{array}{c}\text { Flexible tank } \\
(\mathrm{kPa})\end{array}$ \\
\hline \multirow{4}{*}{0.6} & Imperial Valley, 1940 & 41.09 & 50.92 & 129.40 & 25.23 & 26.01 & 111.60 \\
\hline & Loma Prieta, 1989 & 67.04 & 93.44 & 126.84 & 71.49 & 75.49 & 126.84 \\
\hline & Northridge (NH), 1994 & 69.45 & 72.36 & 122.62 & 68.72 & 74.62 & 122.62 \\
\hline & Northridge, 1994 & 99.25 & 109.37 & 149.73 & 71.13 & 67.95 & 104.61 \\
\hline \multirow{5}{*}{1.85} & Imperial Valley, 1940 & 19.73 & 19.61 & 31.44 & 12.10 & 12.11 & 34.76 \\
\hline & Loma Prieta, 1989 & 32.19 & 32.58 & 42.37 & 34.32 & 33.94 & 63.23 \\
\hline & Northridge (NH), 1994 & 33.34 & 33.68 & 38.13 & 32.97 & 32.09 & 42.25 \\
\hline & Northridge, 1994 & 47.61 & 48.65 & 82.85 & 34.16 & 34.80 & 80.91 \\
\hline & Kobe, 1995 & 47.17 & 47.35 & 51.88 & 35.57 & 36.79 & 38.40 \\
\hline
\end{tabular}

5. The effect of tank flexibility on the convective pressure is negligible. However, the impulsive hydrodynamic pressure amplifies significantly due to the tank flexibility. The distribution of the impulsive pressure has considerably differed due to the flexibility of the tank. In case of the rigid tank, the maximum impulsive pressure is developed at the base of the tank, while in the flexible tank, it is at nearly one-third height from the base of the tank.

The present study has considered harmonic and real earthquake excitations; nevertheless, similar investigation can further be conducted by considering random seismic forces in- duced due to earthquake ground motion.

\section{REFERENCES}

1 Abaqus User's Manual, Version 6.14, Dassault Systèmes Simulia Corporation, Providence, Rhode Island (RI), USA (2014).

2 Amiri M. and Sabbagh-Yazdi S. R. Ambient vibration test and finite element modeling of tall liquid storage tanks, Thin-Walled Structures, 49(8), 974-983 (2011). https://dx.doi.org/10.1016/j.tws.2011.03.008. 


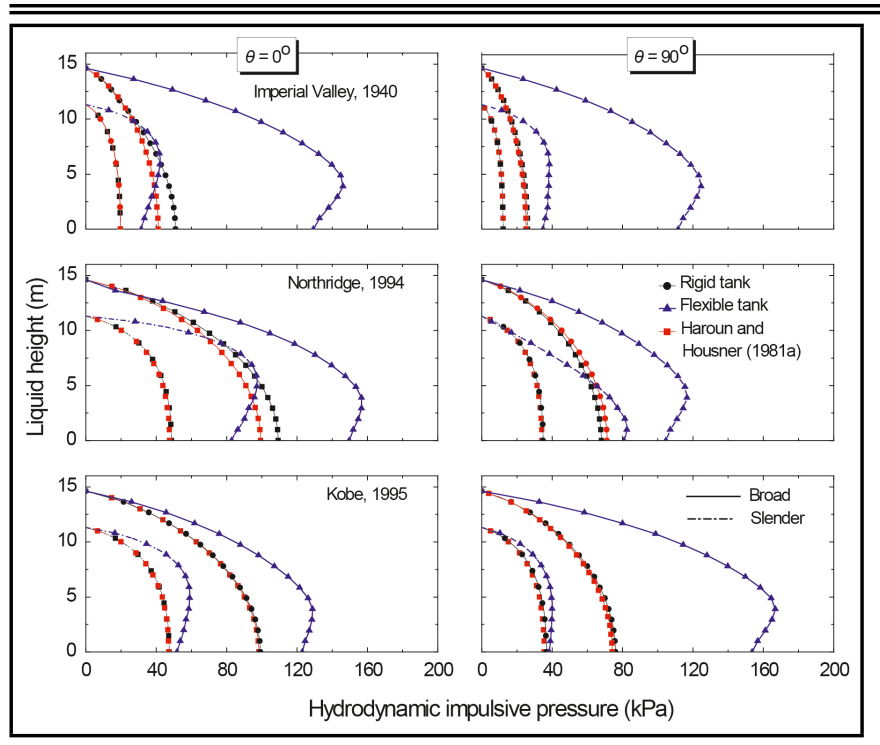

Figure 10. Hydrodynamic impulsive pressures in broad and slender tanks subjected to bi-directional components of earthquakes using FE model.

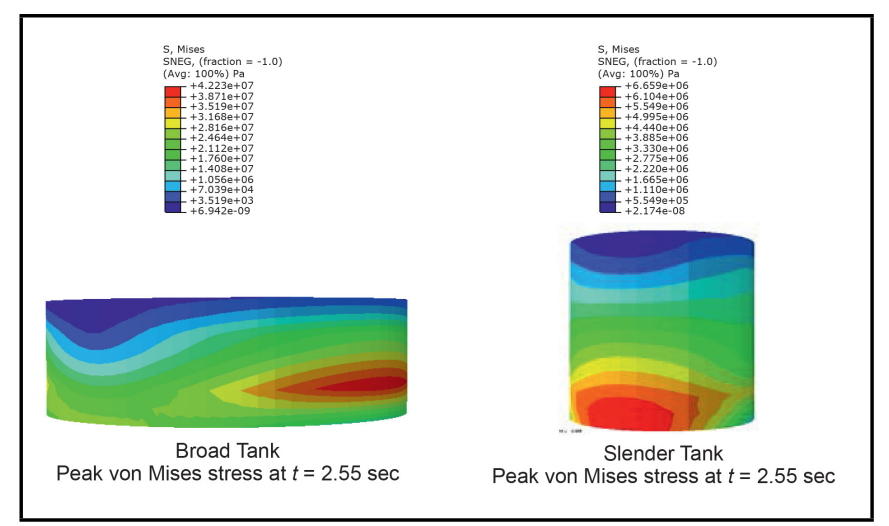

Figure 11. von Mises stress in broad and slender tanks subjected to Imperial Valley, 1940 earthquake.

3 API Standard 650, Welded tanks for oil storage, Washington, D.C., American Petroleum Institute (API) Standards, Washington D.C., USA (2008).

4 ASCE/SEI 7-10, Minimum design loads for buildings and other structures, American Society of Civil Engineers (ASCE), Reston, Virginia (VA), USA (2010).

5 Barton D. C. and Parker J. V. Finite element analysis of the seismic response of anchored and unanchored liquid storage tanks, Earthquake Engineering and Structural Dynamics, 15(3), 299-322, (1987). https://dx.doi.org/10.1002/eqe.4290150303.

6 Bayraktar A., Sevim B., Altunişik A. C., Türker T. (2010), Effect of the model updating on the earthquake behavior of steel storage tanks, Journal of Constructional Steel Research, 66 (3), 462-469. https://dx.doi.org/10.1016/j.jcsr.2009.10.006.

7 Bhaskararao A. V. and Jangid R. S. Optimum viscous damper for connecting adjacent SDOF structures for harmonic and stationary white-noise random excitations, Earthquake Engineering and Structural Dynamics, 36, 563-571, (2007). https://dx.doi.org/10.1002/eqe.636.
8 Carlsson H., Finite element analysis of structure-acoustic systems; formulations and solution strategies, TVSM 1005, Structural Mechanics, LTH, Lund University, Lund, Sweden (1992).

9 Chen Y. H., Hwang W. S. and Ko C. H., Sloshing behaviors of rectangular and cylindrical liquid tanks subjected to harmonic and seismic excitations, Earthquake Engineering and Structural Dynamics, 36(12), 1701-1717, (2007). https://dx.doi.org/10.1002/eqe.713.

10 Clough D. P. Experimental evaluation of seismic design method for broad cylindrical tanks, Earthquake Engineering Research Center Report, UCB/EERC 77-10, (1977).

11 Clough R. W., Niwa A. and Clough D. P. Experimental seismic study of cylindrical tanks, Journal of the Structural Division, American Society of Civil Engineers (ASCE), 105(12), 2565-2590, (1979).

12 Elkholy S. A., Elsayed A. A., El-Ariss B. and Sadek S. A. Optimal finite element modeling for modal analysis of liquid storage circular tanks, International Journal of Structural Engineering, 5(3), 207-241, (2014). https://dx.doi.org/10.1504/IJSTRUCTE.2014.063034.

13 Eurocode 8, Design of structures for earthquake resistance, Part 4: Silos, tanks and pipelines, European Committee for Standardization (ECS), Brussels, Belgium, (2006).

14 Everstine G. C., Finite element formulations of structural acoustics problems, Computers and Structures, 65(3), 307-321, (1997). https://dx.doi.org/10.1016/S00457949(96)00252-0.

15 Fiore A., Demartino C., Greco R., Rago C., Sulpizio C and Vanzi I. Seismic performance of spherical liquid storage tanks: a case study, International Journal of $\mathrm{Ad}$ vanced Structural Engineering, 10(2), 121-130, (2018). https://dx.doi.org/10.1007/s40091-018-0185-1.

16 Gates W. E. Elevated and ground supported steel storage tanks, In: Leeds, D. J. (Ed.), Imperial County, California, Earthquake, Earthquake Engineering Research Institute, Oakland, California (CA), USA, (1980).

17 Ghaemmaghami A. R., Kianoush M. R. Effect of wall flexibility on dynamic response of concrete rectangular tanks under horizontal and vertical ground motions, Journal of Structural Engineering, American Society of Civil Engineers (ASCE), 136(4), 441451, (2010). https://dx.doi.org/10.1061/(ASCE)ST.1943541X.0000123.

18 Godoy L. A. Buckling of vertical oil storage steel tanks: Review of static buckling studies, Thin-Walled Structures, 103, 1-21, (2016). https://dx.doi.org/10.1016/j.tws.2016.01.026.

19 Goudarzi M. A. and Sabbagh-Yazdi S. R. Numerical investigation on accuracy of mass spring models for cylindrical tanks under seismic excitation, International Journal of Civil Engineering, 7(3), 190-202, (2009). http://ijce.iust.ac.ir/article-1-290-en.html.

${ }^{20}$ Hall J. F. Northridge earthquake of January 17, 1994: Reconnaissance report, Earthquake Spectra, Supplement C, 11, 1-514, (1995). 
21 Hamdan F. H. Seismic behavior of cylindrical steel liquid storage tanks, Journal of Constructional Steel Research, 53(3), 307-333, (2000). https://dx.doi.org/10.1016/S0143974X(99)00039-5.

22 Hanson R. D. Behavior of storage tanks, the Great Alaska earthquake of 1964: Engineering, National Academy of Science, Washington D.C., USA, 331-339, (1973).

23 Haroun M. A. Behavior of unanchored oil storage tanks: Imperial Valley earthquake, Journal of Technical Topics Civil Engineering, 109(1), 23-40, (1983a).

24 Haroun M. A. Vibration studies and test of liquid storage tanks, Earthquake Engineering and Structural Dynamics, 11(2), 179-206, (1983b). https://doi.org/10.1002/eqe.4290110204.

25 Haroun M. A. and Housner G. W. Earthquake response of deformable liquid storage tanks, Journal of Applied Mechanics, American Society of Mechanical Engineers (ASME), 48(2), 411-418, (1981a). https://dx.doi.org/10.1115/1.3157631.

26 Haroun M. A. and Housner G. W. Seismic design of liquid storage tanks, Journal of the Technical Councils, American Society of Civil Engineers (ASCE), 107, 191-207, (1981b).

27 Hatayama K. Lessons from the 2003 Tokachi-Oki, Japan earthquake for prediction of long-period strong ground motions and sloshing damage to oil storage tanks, Journal of Seismology, 12(2), 255-263, (2008). https://dx.doi.org/10.1007/s10950-007-9066-y.

28 Hosseinzadeh N., Kazem H., Ghahremannejad M., Ahmadi E. and Kazem N. Comparison of API 650-2008 provisions with FEM analyses for seismic assessment of existing steel oil storage tanks, Journal of Loss Prevention in the Process Industries, 26(4), 666-675, (2013). https://dx.doi.org/10.1016/j.jlp.2013.01.004.

29 Housner G. W. Dynamic pressures on accelerated fluid containers, Bulletin of the Seismological Society of America, 47(1), 15-35, (1957).

30 Housner G. W. The dynamic behavior of water tanks, Bulletin of the Seismological Society of America, 53(1), 381387, (1963).

31 Jadhav M. B. and Jangid R. S. Response of base-isolated liquid storage tanks, Shock and Vibration, 11(1), 33-45, (2004). https://dx.doi.org/10.1155/2004/276030.

32 Jaiswal O. R., Rai D. C. and Jain S. K. Review of seismic codes on liquid-containing tanks, Earthquake Spectra, 23(1), 239-260, (2007). https://dx.doi.org/10.1193/1.2428341.

33 Kim H., Choi Y. and Lee Y. Numerical analysis of sloshing impact in horizontally excited prismatic tanks, Progress in Computational Fluid Dynamics, An International Journal, Inderscience Publisher, 17(6), 361-367, (2017). https://dx.doi.org/10.1504/PCFD.2017.088797.

34 Kim J. K., Koh H. M. and Kwahk I. J. Dynamic response of rectangular flexible fluid containers, Journal of Engineering Mechanics, American Society of Civil Engineers (ASCE), 122(9), 807-817, (1996). https://dx.doi.org/10.1061/(ASCE)07339399(1996)122:9(807).
35 Kormanikova E. and Kotrasová K. Multiscale modeling of liquid storage laminated composite cylindrical tank under seismic load, Composites Part B: Engineering, 146, 189-197, (2018). https://dx.doi.org/10.1016/j.compositesb.2018.03.011.

36 Kotrasová K. and Kormanikova E. The study of seismic response on accelerated contained fluid, Advances in Mathematical Physics, Article ID 1492035, 1-9, (2017). https://dx.doi.org/10.1155/2017/1492035.

37 Mackerle J. Fluid-structure problems, finite element and boundary element approaches a bibliography (1995-1998), Finite Elements in Analysis and Design, 31(3), 231-240, (1999). https://dx.doi.org/10.1016/S0168-874X(98)000651.

38 Malhotra P. K. Earthquake induced sloshing in tanks with insufficient freeboard, Structural Engineering International: Journal of the International Association for Bridge and Structural Engineering (IABSE), 16(3), 222-225, (2006). https://dx.doi.org/10.2749/101686606778026466.

39 Malhotra P. K. and Veletsos A. S. Uplifting response of unanchored liquid storage tanks, Journal of Structural Engineering, American Society of Civil Engineers (ASCE), 120(12), 3525-3547, (1994). https://dx.doi.org/10.1061/(ASCE)07339445(1994)120:12(3525).

40 Malhotra P. K., Wenk T. and Wieland M. Simple procedure for seismic analysis of liquid storage tanks, Structural Engineering International, International Association for Bridge and Structural Engineering (IABSE), Zurich, Switzerland, 10(3), 197-201, (2000). https://dx.doi.org/10.2749/101686600780481509.

41 Manos G. C. Evaluation of the earthquake performance of anchored wine tanks during the San Juan, Argentina, 1977 earthquake, Earthquake Engineering and Structural Dynamics, 20(12), 1099-1114, (1991). https://dx.doi.org/10.1002/eqe.4290201202.

42 Manos G. C. and Clough R. W. Tank damage during the May 1983 Coalinga earthquake, Earthquake Engineering and Structural Dynamics, 13(4), 449-466, (1985). https://dx.doi.org/10.1002/eqe.4290130403.

43 Morand H. and Ohayon R. Fluid structure interaction: applied numerical methods, Wiley, New York (NY), USA, (1995).

44 Moslemi M. and Kianoush M. R. Parametric study on dynamic behavior of cylindrical ground-supported tanks, Engineering Structures, 42, 214-230, (2012). https://dx.doi.org/10.1016/j.engstruct.2012.04.026.

45 NZS 1170.5 Structural design actions Part 5: Earthquake actions - New Zealand, New Zealand Standard (NZS), Wellington, New Zealand, (2004).

46 Ormeno M., Larkin T. and Chouw N. Evaluation of seismic ground motion scaling procedures for linear time-history analysis of liquid storage tanks, Engineering Structures, 102, 266-277, (2015). https://dx.doi.org/10.1016/j.engstruct.2015.08.024. 
47 Ozdemir Z., Souli M. and Fahjan Y. M. Application of nonlinear fluid-structure interaction methods to seismic analysis of anchored and unanchored tanks, Engineering Structures, 32(2), 409-423, (2010). https://dx.doi.org/10.1016/j.engstruct.2009.10.004.

48 Panchal V. R. and Soni D. P. Seismic behavior of isolated fluid storage tanks: a-state-of-the-art review, KSCE Journal of Civil Engineering, 18(4), 1097-1104, (2014). https://dx.doi.org/10.1007/s12205-014-0153-7.

49 Park J. H., Bae D. and Oh C. K. Experimental study on the dynamic behavior of a cylindrical liquid storage tank subjected to seismic excitation, International Journal of Steel Structures, 16(3), 935-945, (2016). https://dx.doi.org/10.1007/s13296-016-0172-y.

50 Phan H. N., Paolacci F. and Alessandri S. Enhanced seismic fragility analysis of unanchored steel storage tanks accounting for uncertain modeling parameters, Journal of Pressure Vessel Technology, The American Society of Mechanical Engineers (ASME), (2018). https://dx.doi.org/10.1115/1.4039635.

51 Rahmati M., Mirdamadi H. R. and Goli S. Divergence instability of pipes conveying fluid with uncertain flow velocity, Physica A: Statistical Mechanics and its Applications, 491, 650-665, (2018). https://dx.doi.org/10.1016/j.physa.2017.09.022.

52 Rebouillat S. and Liksonov D. Fluid-structure interaction in partially filled liquid containers: a comparative review of numerical approaches, Computers and Fluids, 39(5), 739-746, (2010). https://dx.doi.org/10.1016/j.compfluid.2009.12.010.

53 Rodriguez C. G., Flores P., Pierart F. G., Contzen L. R. and Egusquiza E. Capability of structuralacoustical FSI numerical model to predict natural frequencies of submerged structures with nearby rigid surfaces, Computers and Fluids, 64, 117-126, (2012). https://dx.doi.org/10.1016/j.compfluid.2012.05.011.

54 Ruiz R. O., Lopez-Garcia D. and Taflanidis A. A. An efficient computational procedure for the dynamic analysis of liquid storage tanks, Engineering Structures, 85, 206-218, (2015). https://dx.doi.org/10.1016/j.engstruct.2014.12.011.

55 Saha S. K., Matsagar V. A. and Jain A. K. Comparison of base-isolated liquid storage tank models under bidirectional earthquakes, Natural Science, 5(8A), 27-37, (2013a). https://dx.doi.org/10.4236/ns.2013.58A1004.

56 Saha S. K., Sepahvand K., Matsagar V. A. and Jain A. K., Marburg S. Stochastic analysis of base-isolated liquid storage tanks with uncertain isolator parameters under random excitation, Engineering Structures, 57, 465-474, (2013b). https://dx.doi.org/10.1016/j.engstruct.2013.09.037.

57 Saha S. K., Sepahvand K., Matsagar V. A., Jain A. K. and Marburg S. Fragility analysis of base-isolated liquid storage tanks under random sinusoidal base excitation using generalized polynomial chaos expansion-based simulation, Journal of Structural Engineering, American society of Civil Engineers (ASCE), 142(10), 040160591-12, (2016). https://dx.doi.org/10.1061/(ASCE)ST.1943$541 X .0001518$.
58 Sandberg G., Wernberg P. A. and Davidson P. Fundamentals of fluid-structure interaction, International Centre for $\mathrm{Me}$ chanical Science, Courses and Lectures No. 505 on Computational Aspects of Structural Acoustics and Vibration, Edited by Sandberg G., Ohayon R., Springer Wien, New York (NY), USA, 23-101, (2008).

59 Shahverdiani K., Rahai A. R. and Khoshnoudian F., Fluidstructure interaction in concrete cylindrical tanks under harmonic excitations, International Journal of Civil Engineering, 6(2), 132-141, (2008). http://ijce.iust.ac.ir/article-1201-en.html.

60 Spritzer J. M. and Guzey S. Review of API 650 Annex E: Design of large steel welded aboveground storage tanks excited by seismic loads, Thin-Walled Structures, 112, 41-65, (2017). https://dx.doi.org/10.1016/j.tws.2016.11.013.

61 Steinbrugge K. V. and Rodrigo F. A. The Chilean earthquakes of May 1960: A structural engineering viewpoint, Bulletin of Seismological Society of America, 53(2), 225307, (1963).

62 Veletsos A. S. Seismic effects in flexible liquid storage tanks, In the Proceeding of the $5^{\text {th }}$ World Conference on Earthquake Engineering (5WCEE), 25-29 June, Rome, Italy, 1, 630-639, (1973).

63 Veletsos A. S. and Yang J. Y., Dynamics of fixed base liquid storage tanks, In the Proceeding of the U.S.-Japan Seminar on Earthquake Engineering Research with Emphasis on Lifeline Systems, Japan Society for Promotion of Earthquake Engineering, 8-12 November, Tokyo, Japan, 317341, (1976).

64 Virella J. C., Prato C. A. and Godoy L. A. Linear and nonlinear 2-D finite element analysis of sloshing modes and pressures in rectangular tanks subject to horizontal harmonic motions, Journal of Sound and Vibration, 312(3), 442-460, (2008a). https://dx.doi.org/10.1016/j.jsv.2007.07.088.

65 Virella J. C., Suarez L. E. and Godoy L. A. A static nonlinear procedure for the evaluation of the elastic buckling of anchored steel tanks due to earthquake, Journal of Earthquake Engineering, 12(6), 999-1022, (2008b). https://dx.doi.org/10.1080/13632460701672714.

66 Virella J.C., Godoy L.A. and Suarez L. E. Dynamic buckling of anchored steel tanks subjected to horizontal earthquake excitation, Journal of Constructional Steel Research, 62(6) 521-531, (2006). https://dx.doi.org/10.1016/j.jcsr.2005.10.001.

67 Wang X. and Bathe K. J. Displacement/pressure based mixed finite element formulations for acoustic fluidstructure interaction problems, International Journal for Numerical Methods in Engineering, 40(11), 20012017, (1997). https://dx.doi.org/10.1002/(SICI)10970207(19970615)40:11<2001::AID-NME152>3.0.CO;2W.

68 Zienkiewicz O. C. and Taylor R. L. The finite element method, volume 1: The basis, $5^{\text {th }}$ Edition, ButterworthHeinemann, Oxford, UK, (2000). 